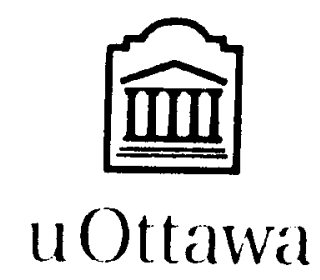

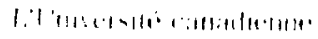

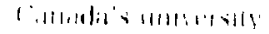


FACULTÉ DES ÉTUDES SUPÉRIEURES ET POSTOCTORALES
IIII

u Ottawa

L'Université canadienne Canada's university
FACULTY OF GRADUATE AND POSDOCTORAL STUDIES

Renée Lafleur

AUTEEUR DE LA THESE / AUTHOR OF THESIS

M.Sc. (Human Kinetics)

GRADE IDEGREE

School of Human Kinetics

FACULTE, ECOLE, DEPARTEMENT / FACULTTY, SCHOOL, DEPARTMENT

Attentional Demands During a Goal-Directed Blind Navigation Task in Young and Older Adults

TITRE DE LA THESSE / TITLE OF THESIS

Yves Lajoie

DIRECTEUR (DIRECTRICE) DE LA THESE / THESIS SUPERVISOR

Nicole Paquet

CO-DIRECTEUR (CO-DIRECTRICE) DE LA THESE ITHESIS CO-SUPERVISOR

EXAMINATEURS (EXAMINATRICES) DE LA THĖSE / THESIS EXAMINERS

Heidi Sveistrup

François Tremblay

Gary W. Slater

Le Doyen de la Faculté des études supérieures et postdoctorales / Dean of the Faculty of Graduate and Postdoctoral Studies 


\section{Attentional demands during a goal-directed blind navigation task in young and older adults}

by Renée Lafleur

Thesis submitted in partial fulfillment of the requirement for the degree of Masters of Sciences in Human Kinetics (M.Sc.)

Faculty of Health Sciences, School of Human Kinetics

University of Ottawa

CRenée Lafleur, Ottawa, Canada, 2009 


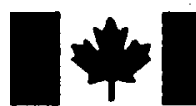

\author{
Library and Archives \\ Canada \\ Published Heritage \\ Branch \\ 395 Wellington Street \\ Ottawa ON K1A ON4 \\ Canada
}

Bibliotheque et

Archives Canada

Direction du

Patrimoine de l'édition

395, rue Wellington

Ottawa ON K1A ON4

Canada
Your file Votre référence
ISBN: $978-0-494-61265-1$
Our file Notre référence
ISBN: $978-0-494-61265-1$

\section{NOTICE:}

The author has granted a nonexclusive license allowing Library and Archives Canada to reproduce, publish, archive, preserve, conserve, communicate to the public by telecommunication or on the Internet, loan, distribute and sell theses worldwide, for commercial or noncommercial purposes, in microform, paper, electronic and/or any other formats.

The author retains copyright ownership and moral rights in this thesis. Neither the thesis nor substantial extracts from it may be printed or otherwise reproduced without the author's permission.
AVIS:

L'auteur a accordé une licence non exclusive permettant à la Bibliothèque et Archives Canada de reproduire, publier, archiver, sauvegarder, conserver, transmettre au public par télécommunication ou par l'Internet, prêter, distribuer et vendre des thèses partout dans le monde, à des fins commerciales ou autres, sur support microforme, papier, électronique et/ou autres formats.

L'auteur conserve la propriété du droit d'auteur et des droits moraux qui protège cette thèse. $\mathrm{Ni}$ la thèse ni des extraits substantiels de celle-ci ne doivent être imprimés ou autrement reproduits sans son autorisation.
In compliance with the Canadian Privacy Act some supporting forms may have been removed from this thesis.

While these forms may be included in the document page count, their removal does not represent any loss of content from the thesis.
Conformément à la loi canadienne sur la protection de la vie privée, quelques formulaires secondaires ont été enlevés de cette thèse.

Bien que ces formulaires aient inclus dans la pagination, il n'y aura aucun contenu manquant. 


\section{Summary}

Spatial navigation is a common yet very important activity in everyday life. Errors in navigation, which usually involve miscalculations of distance and direction, derive from a variety of deficits, including neurological diseases, injuries, as well as aging.

In a navigation task designed to assess the ability to reach a target location without vision, young and older adults showed statistically significant age differences in dual-task costs. It was also shown that dual-task costs vary as a function of task condition. Specifically, the navigation measures (traveled distance, angular deviation and body rotation) were significantly larger in older than young adults. There was no significant effect of task on those measures, with the exception of traveled distance. Conversely, the effect of age on reaction times was non-significant, but there was a main effect of condition on reaction time, with reaction times being significantly longer during the dual-task condition than during the sitting condition. 


\section{Forward}

This thesis is part of the research in which I participated during my master's studies at the University of Ottawa during the last two years. I would like to take the opportunity to thank all the individuals whose contributions are greatly appreciated. First of all, I would like to thank my thesis supervisor Dr. Yves Lajoie and co-supervisor Dr. Nicole Paquet for conveying the importance of learning how to conduct scientific research, and more importantly how to write about it. Their expertise in all things scientific, and unwavering guidance and support in all things un-scientific are valued qualities that any student would be blessed with in a professor.

To Dr. Lajoie, for introducing me to motor control and for encouraging me to pursue this research opportunity. Your confidence in my abilities always inspires me to reach higher. Furthermore, your steadiness and ability to remain unruffled in times of stress kept me grounded, and for that I thank you.

To Dr. Paquet, for your devotion to the study and for your critical appraisal of this manuscript. Responding to emails and answering questions with such super-human swiftness helped me improve my writing style greatly and encourage me to strive for excellence. Your passion for research is infectious and along with your encouragement, helped me sustain my efforts when times were difficult.

To Fatimeh Sabagh-Yazdi, for making time in your already hectic schedule to help with the testing. Thank you for contributing your experience of navigation research, without which, testing and measuring would not have been as precise and efficient.

To my colleagues, students and seniors for their participation in this study. A special thanks to the senior centre coordinators at the Heron Road Community Centre, Debbie and Noreen, who made it possible to conduct our research in their gymnasium gratuitously.

Lastly, I would like to thank my family and friends for their support. Thank you for listening and for offering advice even when you had no idea of what I was talking about. 
ADE - angular deviation

ARCTAN - arc tangent

CM - centimeters

CNS - central nervous system

COP - center of pressure

CPG - central pattern generator

DF - degree of freedom

DT - dual-task

HAT - head, arms and trunk

M - meters

MSEC - milliseconds

NAV - navigation alone condition

RT - reaction time

SD - standard deviation

SI - primary somatosensory cortex

SII - secondary somatosensory cortex

Sig. - significance

SQRT - square root

WWT - walking while talking test 
Summary

\section{Table of Contents}

Forward

Abbreviations

Table of Contents

List of Figures and Tables

Chapter I- General introduction

Chapter II - Review of literature

1.0 Navigational control

2.0 Sensory system

2.1 Proprioception

2.1.1 Somatosensors

2.1.2 Vestibular apparatus

2.1.3 Proprioception and aging

2.2 Vision

2.2.1 Vision and aging $\quad 19$

$\begin{array}{ll}3.0 \text { Cognitive system } & 20\end{array}$

3.1 Perception 21

3.2 Attention 24

3.3 Processing 28

3.4 Spatial memory and cognitive orientation $\quad 30$

3.4.1 Path integration 32

3.5 Cognition and aging $\quad 33$

4.0 Motor system

4.2 Gait $\quad 36$

4.3 Posture control, gait and aging $\quad 38$

5.0 Research on navigation

$\begin{array}{ll}5.2 \text { Older adults } & 47\end{array}$

6.0 Research on reaction times 48

7.0 In which direction is navigation research heading? 50

Chapter III -Attentional demands of a goal-directed blind navigational task in young and $\quad 52$ older adults

1.0 Objectives

2.0 Hypotheses

3.0 Methods

3.1 Subjects

54

3.2 Material

55

3.3 Procedures

55

3.4 Measures

58

4.0 Statistical analysis 
$\begin{array}{ll}5.0 \text { Results } & 64\end{array}$

$\begin{array}{ll}5.1 \text { Navigation measures } & 65\end{array}$

5.2 Reaction times 71

$\begin{array}{ll}\text { 6.0 Discussion } & 75\end{array}$

6.1 Navigation and reaction times $\quad 75$

6.1.1 Traveled distance 75

6.1.2 Angular deviation and body rotation $\quad 76$

6.1.3 Reaction times 78

6.2 Impact of aging on navigation and reaction times $\quad 80$

6.3 Limitations and future considerations $\quad 83$

$\begin{array}{ll}\text { Chapter IV - Conclusion } & 87\end{array}$

$\begin{array}{lr}\text { Bibliography } & 89\end{array}$

$\begin{array}{ll}\text { Appendices } & 103\end{array}$

$\begin{array}{ll}\text { Appendix I - Ethics approval } & 104\end{array}$

$\begin{array}{ll}\text { Appendix II - Health Status Questionnaire } & 106\end{array}$

Appendix III - Mini-mental state examination and interpretation 108

$\begin{array}{ll}\text { Appendix IV - Consent form } & 112\end{array}$ 


\section{List of Figures and Tables}

Figure 1: Anatomy of a muscle spindle (Marieb, 1999) 10

Figure 2: Stretch reflex of the calf muscle (Dietz, 2002) 11

Figure 3: Inner ear (Encyclopedia Britannica, 2009) 13

Figure 4: The macula utriculi of the inner ear (Encyclopedia Britannica, 2009) 14

Figure 5: Somatosensory cortex and association areas 23

Figure 6: A comparison of postural alignment across thirty years (National 40

Osteoporosis Foundation, 2009)

Figure 7: Screen shot of the software used to analyze the oral response 59

Figure 8: An aerial view of the experimental set-up $\quad 61$

Figure 9: Illustrations of the start line, a target and a footmark 63

Figure 10: Means \pm SD of traveled distance of young and older adults 66

Figure 11 Means \pm SD of angular deviation of young and older adults $\quad 68$

Figure 12: Means \pm SD of body rotation in young and older adults $\quad 70$

Figure 13: Means \pm SD of reaction times in young and older adults $\quad 72$

Figure 14: Means \pm SD of reaction times in young adults $\quad 73$

Figure 15: Means \pm SD of reaction times in older adults 74

Table 1: Descriptive statistics of experimental groups 54

Table 2: Representation of the stimulus delivery during twenty trials 58

Table 3: Two-way ANOVA results of the effect of condition and group on $\quad 65$ traveled distance

Table 4: Two-way ANOVA results on the effect of condition and group on 67 angular deviation

Table 5: Two-way ANOVA results on the effect of condition and group on body 69 rotation

Table 6: Two-way ANOVA results on the effect of condition and group on reaction times 


\section{Chapter I}

General Introduction 
Most activities of daily living require the processing of sensory inputs and the application of learned motor skills, together with cognitive processing to execute the appropriate action. Spatial navigation is an example of this process. It is defined by Gallistel (1990) as the process of determining and maintaining a course or trajectory from one place to another. A navigation task could be as simple as walking across a room to turn on a lamp, or as complex as maneuvering through a crowded supermarket to acquire a list of purchases. However different in complexity these tasks might be, a certain amount of alertness and concentration is required to maintain the destined route and successfully reach a target location.

Certain constraints, whether they are task-related, individual or environmental, may induce errors in navigation. These errors are indicated by a deviation from the desired trajectory or target. A lateral or sideways deviation from a trajectory is referred to as a direction error and a longitudinal deviation, undershoot/overshoot, from a specified target location is referred to as a distance error (Loomis et al., 1992).

Distance and/or direction errors often occur during navigation for a variety of reasons. With low/impaired vision, a person may incorrectly judge the distance and surpass, or fall short of the destination (Rieser et al., 1990). A loss or reduction of gaitrelated feedback may prevent an individual to accurately perceive the displacement of the body during walking towards the target (Böök and Gärling, 1981). Furthermore, when a person's attention is inadequate or even divided with another task, it provokes distractions from the task at hand. Aging individuals are more likely to manifest navigation errors than young able-bodied persons as a result of individual constraints, which develop naturally with age. 
There exists several models that describe aging, which can be divided into two categories; primary and secondary aging (Shumway-Cook \& Woollacott, 2001, p.222). Primary aging focuses on the internal causes of aging and specifies that the lifespan is genetically determined, whereas secondary aging suggests that aging is influenced by external causes, or environmental factors such as pollution, bacteria, viruses, foods and toxins that damage the organism. As we are mainly interested in healthy older adults (without pathology), we will remain within the confines of the first model to describe the changes that can affect the performance of a navigation task. It is important to note, however, that neural aging does not necessarily mean an overall decline of functions, but that a decline might be limited to specific structures. Dysfunction should not be generalized; it emerges through the interaction of capacities of the individual carrying out particular tasks within specific environmental contexts (Shumway-Cook \& Woollacott, 2001, p.224). Individual constraints that occur through primary aging might include a decline in peripheral sensation, in vestibular function or in the ability to concentrate.

In addition to unsuccessfully reaching the destination, another potential consequence of navigation error is the involuntarily collision with environmental structures or objects. Aging populations are more at risk of falling from a navigation error and suffer injury (Sturnieks et al., 2008). Among Canadians over the age of 65 for example, falls account for $85 \%$ of all injury hospitalizations (Canadian Institute for Health Information, 2003). Contributions made by health and community service organizations, as well as by the academic community to the matter of fall prevention are therefore of utmost importance.

In order to develop strategies that are related to navigation disabilities, one aspect of human locomotion must be further studied, which is divided attention during spatial 
navigation in the absence of vision. The underlying mechanisms involved in blind navigation must be detailed, as well as the impact of aging on them, by inspecting the findings that have emerged from past research. Based on these findings, the specific issues that are addressed in this study, as well as the hypotheses pertaining to these issues are determined, followed by an outlined method of research. The design helps us have a better understanding of the effects of aging on various systems and how they contribute to the quality of a healthy, older person's performance during a navigation task. 
Chapter II

\section{Review of Literature}


1.0 Navigation control through the sensory, cognitive and motor systems

People can view a target, close their eyes, walk towards it and reach it quite accurately (Rieser et al., 1990). In order to complete this task successfully, the scale of a person's actions relative to their perception must be accurate, stressing the importance of the sensory, motor and cognitive systems. Successful interactions with the environment also necessitate a large amount of alertness (Shumway-Cook \& Woollacott, 2001, p.241). There is a great need to concentrate cognitive resources in blind navigation, because the most important sense used during navigation is vision. When vision is absent, large amounts of other sensory inputs need to be interpreted.

The stimuli associated with the proprioceptive, vestibular and visual systems during navigation inform the central nervous system (CNS) of the internal and external conditions of the body. In a goal-directed blind navigation task for example, the target enters the visual field and the information of its location is stored into memory for when the eyes are closed. The walking surface and the position of the body in relation to the target that was seen are perceived by the kinesthetic receptors, and the acceleration with which the person is walking is picked up by the vestibular system. The musculature then executes the motor commands of the CNS and the person continues walking until he or she thinks that the target is reached.

This section shall discuss the type of sensory information that is collected during navigation through the proprioceptive and visual systems. The perceptual and interpretive role of the cognitive system, as well as the concentration of its resources during navigation will be outlined next. The cognitive system has a role in spatial memory and orientation. Lastly, there is a brief outline of the mechanism of the motor system and its role in locomotion. 


\subsection{Sensory systems}

The responsibility of the reception, transmission and treatment of information is assigned to a group of neural structures of the somesthetic system. This network receives input from both external and internal sources and their integration is performed on three levels: receptors, ascending pathways and perception (Marieb, 1999).

Movement is usually experienced in multiple sensory systems and it is especially true during a navigation task; its success relies on input originating from the kinesthetic/proprioceptive, vestibular (internal) and visual (external) systems. When afferent information is integrated and organized properly, successful interactions with the environment occur. However, the task becomes more difficult to execute if the information from one sense contradicts another- we sway, fall or feel sick. When we are unable to receive information from one sense due to injury or illness, we can compensate to a certain extent by focusing on information coming from another (Haywood \& Getchell, 2001). If this situation arises, for example when removing someone's vision during a navigation task, we might not be as accurate in our perceptions and performance.

In this section we shall follow the pathways of sensory information as it travels from the various receptors that are involved in navigation, including those of the proprioceptive and visual systems. The effect of aging on each component of the sensory system and its importance during a goal-directed blind navigation task is discussed at the end of each section. 


\subsection{Proprioception}

The proprioceptive system is essential to locomotion because it provides us with information about the position of the body in space, the position of the body parts in relation to each other, as well as the characteristics of objects with which the body comes into contact (Haywood \& Getchell, 2001). The receptors distributed on the periphery of the body, are divided into two types. The proprioceptors are located in the muscles, joint capsules, ligaments, and under the skin and those located in the inner ear are known as the vestibular apparatus.

Information relative to the internal or external environment presents itself through mechanical and chemical energy and is converted into a nervous impulse (Marieb, 1999). Sensory nerves that transport the impulse from the proprioceptors vary in diameter and branch out considerably when they reach the spinal cord. The differences in size will result in differences in excitability as well as conduction velocity (Dietz, 2002).

\subsubsection{Somatosensors}

Sensory impulses that are received during locomotion are associated to different types of neural fibers and are separated into four groups (I-IV) according to types of input. For example, type Ia fibers relay information on dynamic muscle length, whereas type II fibers relay information on static muscle length. When measured by Golgi tendon organs, tension is transmitted by group Ib fibers (Marieb, 1999). The location of the different types of afferent and efferent fibers can be seen in Figure 1.

Some of these nerve endings will project with either gamma $(\gamma)$ or alpha $(\alpha)$ motor neurons, which in turn activate one of three reflex mechanisms in the grey matter of the spinal cord (Dietz, 2002) - monosynaptic, cutaneous and polysynaptic reflexes. 
Each of these reflex pathways plays a part in the control of locomotion during a navigation task.

The monosynaptic reflex is regulated by group Ia afferent fibers and is named as such because it is characterized by one single synapse occurring between a sensory neuron (Ia fiber) and an alpha motor neuron $(\alpha)$. Only group Ia fibers have direct contact with the motor neurons of the same muscle and due to their large diameter, their afferent input leads to short-latency responses $(\approx 40 \mathrm{~ms}$ ) (Dietz, 2002). As information from the muscular contraction is constantly being transmitted to the CNS by type Ia sensory fibers, it enables a certain amount of voluntary control on the frequency of motor neuron impulses, which becomes important in certain situations (Marieb, 1999). For example, during locomotion, supraspinal influences can modify gait according to environmental demands and ensure accurate movement.

Specifically, supraspinal influences are used to accommodate for ground irregularities during the stance phase and during the swing phase by inhibiting the reflex of the triceps surae. This enables the proper placing of the foot. The limited contribution of type Ia fibers during walking has been examined by using The Hoffmann reflex (Hreflex) (Dietz, 2002). Figure 2 is a representation of the monosynaptic stretch reflex during locomotion. The functional implication of type Ia afferent inputs during the Hreflex include: a) the gastrocnemius/soleus stretch reflex at the end of the stance phase contributes to the compensation for ground irregularities and assists during the push-off phase and b) a decrease of type Ia afferent inputs during the swing phase prevents the extensor stretch reflex during ankle dorsiflexion (Dietz, 2002). 


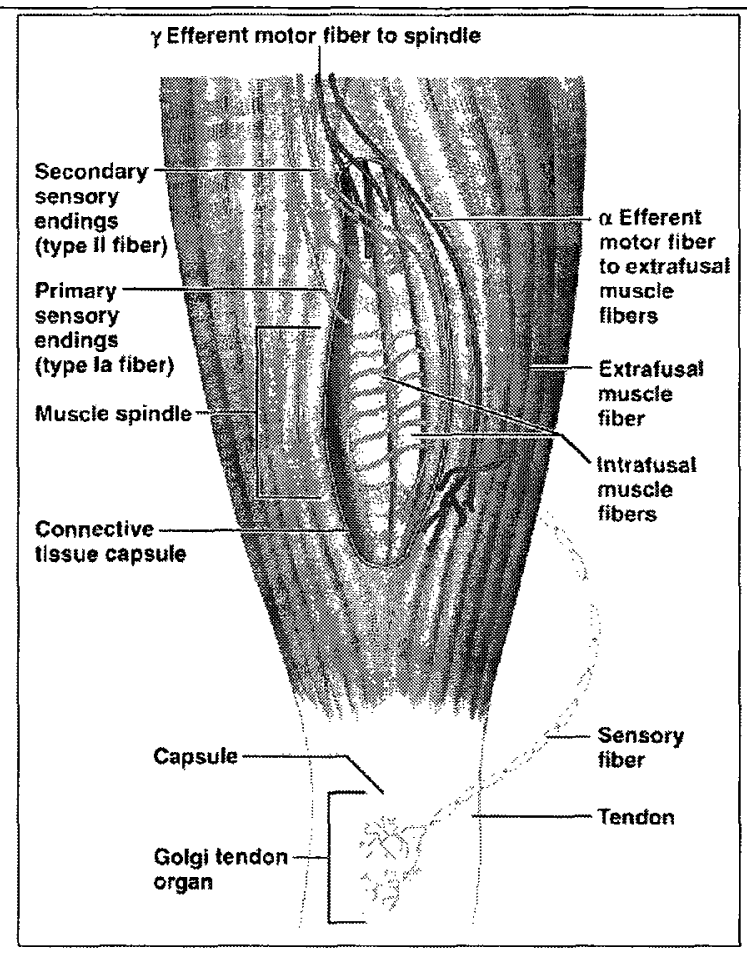

Figure 1: Anatomy of a muscle spindle and tendon. Type Ia afferent fibers are attached to the center of the spindle and type II fibers are located at the extremities of the spindle. Alpha motor neurons are charged with contracting extrafusal muscle fibers, whereas gamma motor neurons directly affect intrafusal fibers in the muscle spindle (Marieb, 1999).

There is also evidence for adaptation of the H-reflex to different types of walking. Llewellyn et al. (1990) demonstrated that the H-reflex was attenuated during narrow beam walking compared to treadmill walking. According to these findings, it was suggested by researchers that the reflex gain should be decreased in a task requiring greater stability (Zehr \& Stein, 1999). Though this type of reflex is the most investigated proprioceptive reflex system, its significance during gait remains unclear due to its sensitivity to small inputs. Thus, it has been suggested that its function should be limited only to compensation for ground differences during locomotion (Dietz, 2002). 

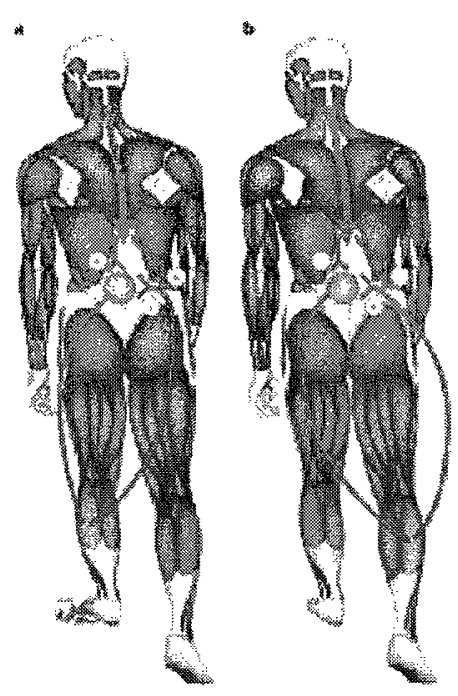

Figure 2: The stretch reflex of the calf muscles during locomotion. a) end of the stance phase contributes to the compensation for ground irregularities and assists during the push-off phase b) the swing phase prevents the extensor stretch reflex during ankle dorsiflexion (Dietz, 2002).

Polysynaptic reflexes from group II muscle efferent also produce compensatory responses during locomotion. Polysynaptic reflexes allow for integration of inputs originating from a wide variety of sources, including input coming from muscle, joint and cutaneous afferent fibers. The integration of massive amounts of information enables a functional response from an assortment of muscle groups, which is needed to restore a person's center of gravity over the feet. The two types of input that are merged in the polysynaptic reflex system are joint-position and load-related information, which help to determine the influence of gravity on the body (Dietz, 2002).

The third type of response appears when the sensory nerve of a limb is directly stimulated (Dietz, 2002). Cutaneous reflexes or triggered reaction (Schmidt \& Wrisberg, 2004) have a longer latency than the polysynaptic reflex ( $80-120 \mathrm{~ms})$ but is too fast to be 
a voluntary action (Schmidt \& Wrisberg, 2004). It seems to serve as an important protective role in response to noxious stimuli at all phases of the step cycle (Zehr \& Stein, 1999). Specifically, cutaneous reflexes are thought to be useful in withdrawal as a response to a stimulus, as well as responding to preserve balance (Yang \& Stein, 1990). Cutaneous reflexes in leg muscles can be adjusted depending on the context in which it is evoked. Furthermore, cutaneous reflexes are nerve specific (Dietz, 2002). These changes in response may reflect organization within the spinal cord in which reflex input during walking is adjusted to maximize compensatory reflex responses (Zehr \& Stein, 1999).

Vestibular-evoked responses are also subject to influence from load-receptor input (Marsden et al., 2002). While standing, each of the subject's legs was subjected to different external forces. It was observed that the body responded by distributing the load equally between both legs. These researchers suggested that there might be an interaction between load-related information and descending input from the vestibular system (Marsden et al., 2002).

\subsubsection{Vestibular apparatus}

The vestibular apparatus, located in the inner ear, constantly relays information to many structures in the nervous system on the position and movement of the head (Marieb, 1999). The inner ear is comprised of two structures: the bony labyrinth and the membranous labyrinth. The bony labyrinth is a cavity dug into the temporal bone and the membranous labyrinth is a network of vesicles and membranous ducts that is positioned in the bony labyrinth. The membranous labyrinth is surrounded by a fluid called perilymph and is filled with a fluid called endolymph (Shumway-Cook \& Woollacott, 2001, p.74). Figure 3 is a structural representation of the inner ear. 


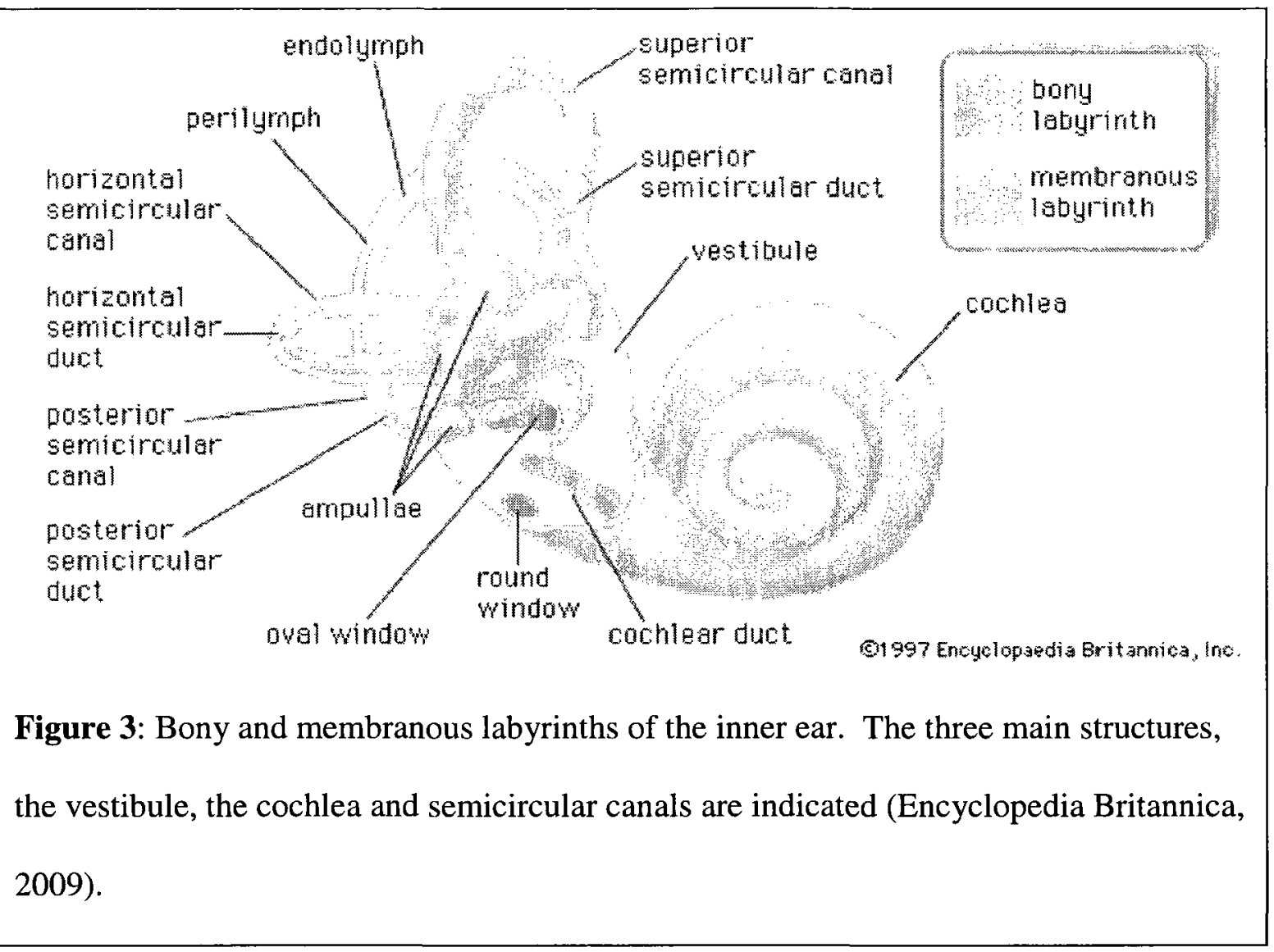

The labyrinth is a system comprised of three structures that float in perilymph, a liquid that resembles spinal fluid. These three structures are the otolith, the cochlea and the semi-circular canals. Only the otoliths and semicircular canals will be described, as the cochlea is concerned with hearing.

The otolith is an oval cavity located in the center of the bony labyrinth and contains two vesicles of the membranous labyrinth: the utricle and saccule, which house static balance receptors called macula utriculi and macula sacculi (Marieb, 1999). The maculae participate in maintaining the head in a normal upright position according to gravitational forces. The macula is an epithelium that contains support cells and sensory cells, which are topped by stereocilia and one unique kinocilium. The cilia penetrate a gelatinous membrane called the otholithic membrane, which is covered by a layer of 
cells, or otoliths, that are dense and help to resist the movement of the membrane. The macula utriculi are horizontal and the cilia are oriented vertically when the head is upright. The macula utriculi react to horizontal accelerations and lateral flexion of the head. Figure 4 is an illustration of the macula utriculi and its response to a change in head position. Conversely, the macula sacculi are almost vertical and the cilia are oriented horizontally in the otholithic membrane, thus reacting to vertical accelerations. The saccule projects itself in the front and is connected to the cochlea, whereas the utricle projects itself in the back and is connected to the semi-circular canals (Marieb, 1999).

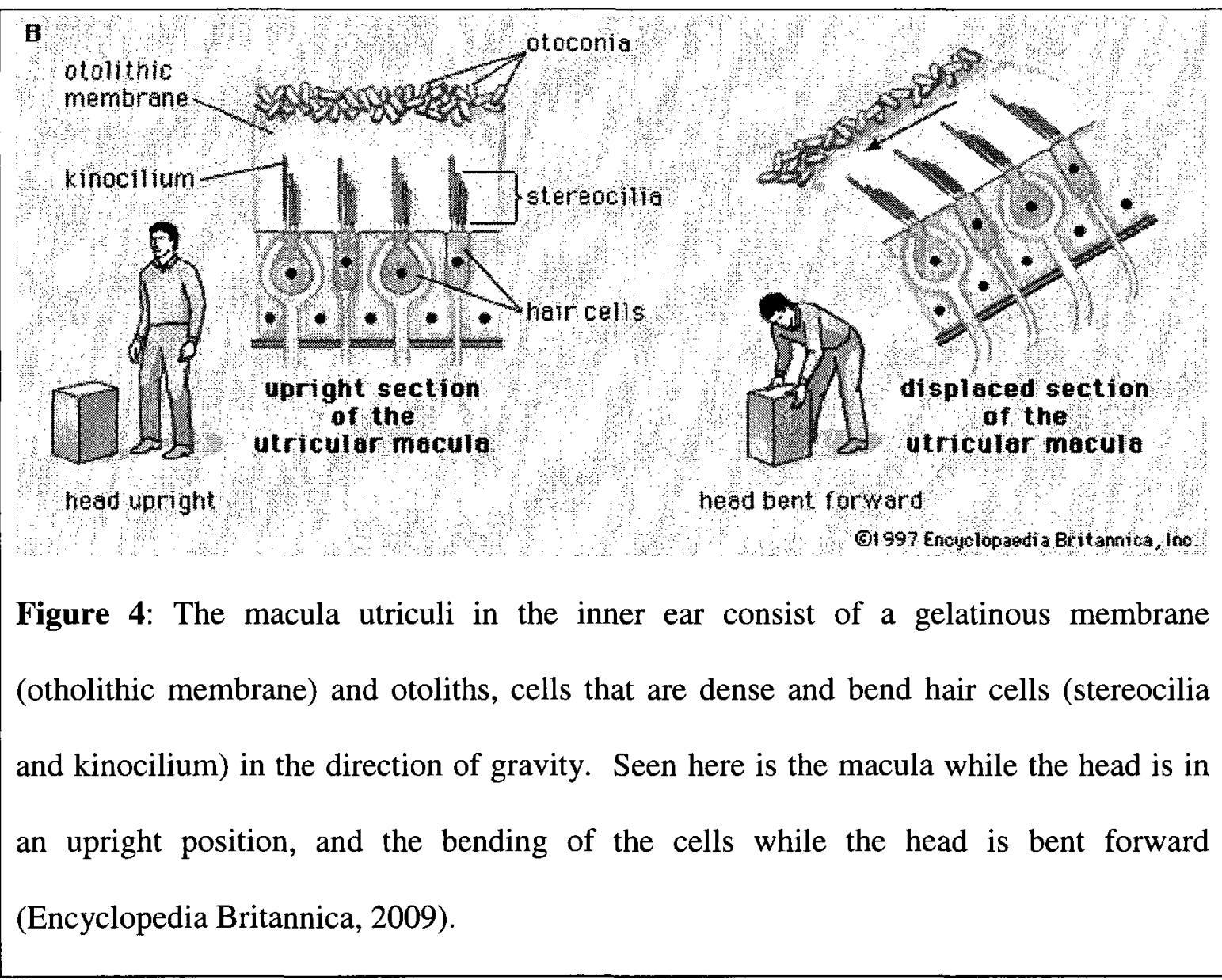

The three semi-circular canals, which begin at the posterior extremity of the vestibule, occupy three planes in space: horizontal, posterior and superior. Each of these 
canals house a semicircular membranous duct that opens into the utricle and contains a bulbous extremity called a membranous ampulla. This structure contains receptors that react to rotational movements of the head and like the maculae they consist of support cells and sensory cells (Marieb, 1999). The stereocilia and kinocilium of the ampullae are projected in a gelatinous substance called the cupula.

When the ampullae react to changes in rotation of the head, the endolymph in the semicircular canals is displaced in the opposite direction of the movement and the crest of the ampullae is temporarily deformed. This induces a change in the firing rate of the vestibular nerve and sends a rhythmic signal to the cerebral cortex. If the rotation of the body becomes constant, the endolymph stabilizes (by moving at the same rate at which the body is moving) and the sensory signals cease. When performing a continuous rotation while being blindfolded for example, it becomes impossible after a few seconds to determine whether the body is moving at a constant speed or if it is immobile. However, if the rotation is suddenly terminated, the endolymph will be displaced in the opposite direction that it was moving, giving an indication of cessation of movement and impression of turning in the other direction (Marieb, 1999).

Pozzo et al. (1990) emphasized the significance of head stabilization in posture control. In this study, head acceleration was observed during various conditions, including regular walking, walking in place and hopping. Subjects were able to keep a relatively stable head position on a vertical axis throughout the different conditions, even during a darkness condition. However, a slight flexion of the head was observed when the subjects were walking in the dark. It was suggested that this angular stabilization could improve the estimation of head linear movement by reducing the uncertainty of the otholithic signal, which is the sum of both gravitational and inertial accelerations. If the 
head is stable in an angular position, the gravity component is constant. This means that any change in otholithic signal would be due to head linear acceleration and ensure precision of linear motion estimation. These findings are significant in that it shows a greater need to stabilize the head during a more complex movement when there is lack of visual information.

With the help of these reflex mechanisms, the control of locomotion is made possible during altering conditions or when the need for accuracy necessitates a quick response. A change in gait might be necessary if there is altering of biomechanical constraints (i.e. injury, weight gain, decrease in range of motion), or when there is a fluctuation in environmental demands, such as an inability to adhere to certain surfaces or displacing the body in new surroundings. The proprioceptive system can detect these changes and help the body to adapt itself quickly to the specified needs (Haywood \& Getchell, 2001).

\subsubsection{Proprioception and aging}

An age-related decline in proprioceptive function might make it more difficult to perceive the changes in the environment and of the body itself in varying circumstances. There are indications that absolute thresholds for perceiving proprioceptive information increase and that older adults experience a decreased sensitivity to pain, pressure and temperature (Haywood \& Getchell, 2001). Aging affects both the quality and quantity of somatosensors (e.g.. Pacinian corpuscles), but the number of receptors lost is more influential on peripheral sensation. As well, there is an estimated $30 \%$ decrease in sensory nerve fibers, which innervate these receptors (Shumway-Cook \& Woollacott, 
2001, p.235). An increase in reliance on other systems, such as the visual and vestibular systems, is usually in store for aging individuals that experience peripheral neuropathy.

The vestibular system is especially useful in the control of balance when visual and somatosensory information is insufficient or conflicting. However, an age-related decline in vestibular function results in a reduction of its ability to reliably serve as a sensory reference. By the age of 70 , there is a $40 \%$ loss of vestibular hair and nerve cells, making it more difficult to perceive the position of the head in relation to the body (Rosenhall \& Rubin, 1975). Consequences of this decline may include a feeling of dizziness. Accompanied with a reduction in kinaesthetic information may cause unsteadiness and a reduction in the amplitude of automatic postural adjustments (Shumway-Cook \& Woollacott, 2001, p.237).

\subsection{Vision}

Vision enables us to identify objects in the environment and to determine their movement relative to the body. When vision plays this role, it is considered as an exteroceptive sense. Vision can also give us information about where our body is in space, where our body parts are in relation to each other, as well as our movement in space. In this case, it is referred to as visual proprioception (Shumway-Cook \& Woollacott, 2001, p.68).

People use vision to coordinate their actions (Laurent et al., 1988), such as when stride adjustments are necessary when approaching a target object on the ground. Even though this study proposes to examine the effects of navigation without vision, a brief outline of its contribution to goal-directed locomotion is crucial in order to establish its effects when it is removed. 
A first glance at the coordination of visually guided locomotion seems to involve the evaluation of distance to a specific target (Laurent \& Thomson, 1988). The performance of adults in many situations is an indication that there is visual information for egocentric (self-to-object) distance and that people can act on it (Rieser et al., 1990).

Most people have the feeling that visual perception is generally accurate. We understand the layout of the world without significant error, and therefore we can interact with it effectively. However, perceived layout is rarely accurate enough to account for the success of visually guided behavior (Bridgeman \& Hoover, 2008). Visual perception might show systematic errors leading to underestimating or overestimating of distance within a certain range, which means that precise action would be coordinated only indirectly with visual perception (Gilinsky, 1951).

It is important to distinguish a perceived distance to a target from an estimated distance. Perceived distance consists of the direct product of visual stimulation, such as when a target object is seen. Estimated distance is a cognitive processing of perceived distance, derived from past experience and training, to arrive at a more informed judgment of true distance. Thus, successful interactions do not only depend on accurate perception, they would also depend on compensatory learning mechanisms (Gilinsky, 1951).

When visual cues to a target or environment are reduced, we can imagine that the perception of egocentric distance can be quite difficult. However, if a subject is allowed to see a target that needs to be reached and is blindfolded before commencing the task, the person can still estimate the time and distance necessary to reach the target, by calibrating the proprioceptive information to the distance of the target that was visually perceived (Rieser et al., 1990). 


\subsubsection{Vision and aging}

Changes in the visual system occur naturally with age and some conditions are more prevalent in older adults (Haywood \& Getchell, 2001). The condition known as presbyopia becomes apparent around the age of 40 , and it is characterized by a gradual loss of accommodation to focus on near objects. Accommodation is the change in curvature of the eye's lens in order to view objects of varied distances (Haywood \& Getchell, 2001). The amount of light that reaches the retina in old age (60 years) is one third of that in a young adult and is accompanied by a natural yellowing of the lens. The reduction of light that reaches the eye results in a glare problem in older adults. There are three other visual disturbances that are common in older adults, which can greatly reduce the ability to see clearly and even cause a complete loss of sight.

Opaque areas in the lens, known as cataracts, prevent even more light to reach the retina and result in blurred vision. In glaucoma, the internal pressure of the eye increases, which can lead to loss of sight and a person with age-related maculopathy, will also have blurred vision. This disease affects the central portion of the retina that enables detailed vision.

Changes in the eye may influence visual perception. We can sometimes see a lack of hand-eye coordination, squinting, and unusual head movements to align one's gaze with an object. In the case where vision is reduced, the vestibular system may play a compensatory role. Furthermore, older adults will sometimes under or overreach for objects (Haywood \& Getchell, 2001). Whether or not this is also true in goal-directed walking tasks, it remains to be seen.

It is clear that age-related changes in the sensory systems may affect motor performance, although changes tend to vary widely among older adults. Compensatory 
mechanisms or strategies are solutions for some of these changes, including the use of eyeglasses and good lighting.

\subsection{Cognitive system}

The study of perception and movement can take an information-processing perspective, in which sensory receptors detect a signal in the environment; it is interpreted in the CNS and a motor command is sent to the musculature, which responds (Haywood \& Getchell, 2001). The information processing approach depends on the following assumptions: the human is a processor of information, comparable to a computing machine and all mental operations take time, thus explaining the use of reaction times as a measure of information processing time (Schmidt, 1982). An essential concept to this approach is that of a motor program. Keele (1968) provided this early definition of a motor program:

...a set of muscle commands that are structures before a movement sequence begins, and that allows the entire sequence to be carried out uninfluenced by peripheral feedback (Keele, 1968, p. 387)

It is also implicit that the set of central commands prepared in advance is stored before being used to direct a movement. Therefore, memory is central to the concept of a motor program (Schmidt, 1982).

Conversely, a second perspective can be adopted: that of the ecological perspective, which sees the environment and the individual as an interactive entity. In this school of thought, the individual is not passive and not simply a receiver of information, but that movement emerges from a dynamic interaction of numerous variables in the body, the environment and the task (Haywood \& Getchell, 2001). 
There was considerable conflict between the two action systems approaches in the 1980s, but it has subsided and as noted by Newell (2003), the two camps have "agreed to disagree". The two approaches now operate in parallel, with some researchers attempting to bridge the gap between them, even though the approaches are about two very different things (Schmidt, 2003). The difference is not so much due to competing ideas for the same phenomena than a concern for different kinds of phenomena: a top-down structural approach versus a bottom-up approach to mutual relationship between environmental information and motor behavior.

Considering the availability of various approaches to motor control, we can certainly say that movements happen through the cooperative effort of many brain structures and processes, including those that are related to perception, cognition and action. This section shall follow the control of movement through the stages of perception to action.

\subsection{Perception}

Human movement is based on information about the environment and one's position within it. Actions are also dependent on the integration of sensory and perceptual information. Perception is the process of transforming sensory inputs into meaningful information (Shumway-Cook \& Woollacott, 2001, p.3). It includes the conscious detection of the stimuli's characteristics. Tactile and thermal qualities, as well as pain are detected through somesthetic impulses (Craig \& Rollman, 1999). The vestibular system captures the position of the head in space or any sudden changes in the direction of its movement (Marieb, 1999), and the visual system identifies objects and motion sense (Haywood \& Getchell, 2001). 
Sensory information from the somesthetic system is carried to the sensory cortex and the cerebellum along two separate systems simultaneously, which is referred to as parallelization. The two systems include the dorsal column-medial lemniscal (DC-ML) system and the anterolateral system (AL) (Shumway-Cook \& Woollacott, 2001, p.61). The advantage of having parallel systems is that it enables multiple modes of information processing, providing extra detail and depth to perception.

The dorsal column pathway sends signals about muscle, tendon and joint sensitivity to the somatosensory cortex and higher brain centers. It also carries input on touch, pressure and codes on fine touch. The anterolateral pathway partly contributes to limb proprioception by relaying information on crude touch and pressure and sends information related to temperature and pain to higher brain centers. There is redundancy of information in both ascending pathways, which becomes crucial to prevent complete loss of discrimination in the event of a lesion in one of the tracts (Shumway-Cook \& Woollacott, 2001, p.64).

Information from both ascending pathways goes to the thalamus, as do information coming from the basal ganglia and cerebellum, making it one of the most important processing areas of the brain (Shumway-Cook \& Woollacott, 2001, p.64). However, it is the somesthetic area of the brain that determines the precise characteristics of the stimulus and its localization.

The somatosensory cortex is a major processing area for all the somatosensory modalities and is the origin of conscious awareness of somatosensation (Shumway-Cook \& Woollacott, 2001, p.64). It is divided into three main areas: the primary (SI), secondary (SII) and the posterior parietal cortex. In SI, sensory impulses coming from muscles, joint and cutaneous receptors are integrated to give information about 
movement in a particular area of the body. This information is laid upon a map of the body and is the origin of the spatial processing that is necessary to control movement in our environments. Figure 5 is a representation of the somatosensory cortex and associated areas.

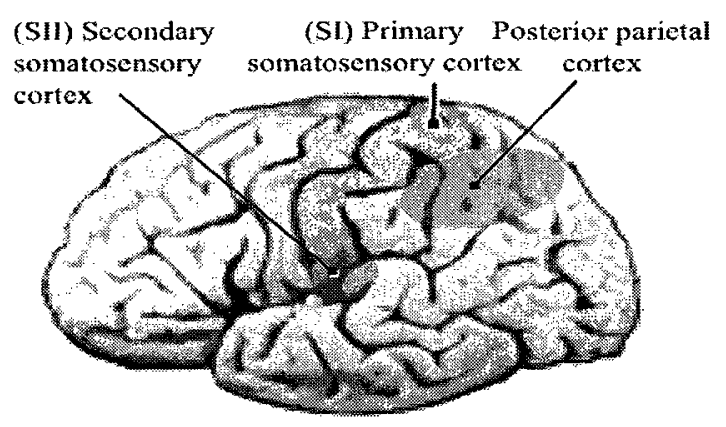

Figure 5: Somatosensory cortex and association areas. Located in the parietal lobe, the somatosensory cortex contains three major divisions: the primary (SI), secondary (SII) and posterior parietal cortex.

Although the vestibular system gives unconscious senses, it is important for the coordination of many motor responses and stabilizes the eyes during walking. The vestibular system can be divided into two parts, a peripheral and a central component. The peripheral component includes the receptors and the central part consists of the four vestibular nuclei and the ascending and descending tracts. As the physiology of the peripheral component has been described in section 1.1.2, we shall now focus on central connections.

The vestibular nuclei receive information coming from the visual and somatosensory receptors, together with information from the vestibular system. 
Information coming from these sources is integrated and commands are sent to neurons of the eye muscles and those responsible for reflexes in the neck and trunk (Marieb, 1999).

Sensory differentiation is a key aspect of sensory processing that supports motor control. In order to accomplish this, the somatosensory cortex detects movement from distinct areas of the body as well as the type of nervous impulse that is perceived by the somatosensors. The sensory information coming into the vestibular nuclei helps to determine head positions and the direction of the movement of the head. This information is integrated with kinesthetic information on limb positions, in order to regain posture control with eye, neck trunk and lower-limb muscle reflex responses. The visual system identifies objects in the environment and determines whether they are in motion. It also helps to locate the body within that environment and supply additional information on joint positions.

This high-level selection of sensory information is complex, but it enhances problem-solving abilities when faced with new situations. The manipulation of information and the application of knowledge needed to solve a problem require many cognitive processing besides perception; it is also dependent on attention and memory.

\subsection{Attention}

Attention is defined as the "information-processing capacity of an individual" (Shumway-Cook \& Woollacott, 2001, p.361). There is an assumption that attention is limited and that performing any task requires a certain amount of it. Accordingly, if two tasks are performed simultaneously and both tasks require more than the total capacity, 
the performance in either or both tasks deteriorates (Shumway-Cook \& Woollacott, 2001, p.362).

Dual-task paradigms involving a cognitive task have been used to assess attentional demands necessary for performing a primary motor task (Bardy \& Laurent, 1991; Brown et al., 1999; Kerr et al., 1985; Lajoie et al., 1993; Lajoie et al., 1996; Teasdale et al., 1993). As indicated by its name, the dual-task paradigm consists of requiring the subject to perform two tasks simultaneously. The first task is the one for which the attentional demand is measured, and the second is the task for which performance modifications are registered, enabling the deduction of demand for the primary task (Bardy \& Laurent, 1991). The extent of which the performance of each task declines indicates the interference between the processes controlling the two tasks, and thus the extent to which the two tasks share attentional resources (Kerr et al., 1985).

There is controversy about the use of a dual-task paradigm to study attention (Woollacott \& Shumway-Cook, 2002). It has been stated that using a dual-task to study attentional demands of postural control requires that changes in performance must be limited to the secondary task with no changes occurring in the primary task (posture) (Teasdale et al., 1993). Discussing changes in the secondary task is the focus, and in this way the associated attentional demands are clearly identified.

Conversely, performance changes in both tasks can be examined during a dualtask experiment (Shumway-Cook \& Woollacott, 2001, p.361). In this case, the dual-task design is used to examine the 1) attentional load of postural tasks and 2) the effects of performing an attentionally demanding cognitive task on the control of posture.

The diverse data on posture-cognition dual tasking presents a challenge to discovering and understanding the precise cognitive task conditions that affect postural 
control (Fraizer and Mitra, 2006). Efforts to impose a theoretical structure on posturecognition outcomes have mostly reflected two broad frameworks. The multiple resource or "capacity" theory views dual-task costs as a consequence of the parallel sharing of a limited set of resources (Wickens, 2008). When the demands of the combined tasks exceed the resource supply, degraded performance is observed in one or both tasks (Fraizer and Mitra, 2006). In contrast, the structure or "bottleneck" theory emphasizes the sequential nature of the dual-task process in terms of the scheduling of information at stimulus encoding, identification or decision-response stages (Pashler, 1994). When interference occurs, the nervous system is said to temporarily postpone operations on one task in favor of operations on the prioritized task, resulting in poor performance on the non-priority task (Fraizer and Mitra, 2006).

In some dual-task studies, the requirements of information processing for the primary task are estimated reaction times (RT) (Bardy \& Laurent, 1991; Lajoie et al., 1993; Teasdale et al., 1993; Lajoie et al., 1996). An RT is the interval of time between the presentation of an unanticipated stimulus to the beginning of a person's response (Schmidt \& Wrisberg, 2004).

Many factors may influence RT, such as the nature of the stimulus and the type of movement being performed. One of the factors that influence the time it takes to start an action is the number of possible stimuli to choose from at a given time. Situations like this are known as choice RT, where the performer must identify the stimulus (e.g. different colored lights) and choose a response according to that stimulus (e.g. pressing buttons with different fingers). As the number of possible stimuli-response pairs increases, the time required to respond to any one of them (choice RT) also increases (Schmidt \& Wrisberg, 2004). This stable linear relationship is known as Hick's law. A 
simple RT is found when there is only one stimulus and one response (Schmidt \& Wrisberg, 2004).

Reaction times have also been found to vary according to task conditions. For example, reaction times are fast in a stable position such as in sitting or standing balance task, and slower in unstable tasks such as walking (Lajoie et al., 1993). A study on balance recovery involving a secondary task found that unexpected platform perturbations require more attention than quiet stance (Brown et al., 1999).

Bardy \& Laurent (1991) studied the attentional demands of walking under various environmental conditions. It was reported that differences in size of a visual target affected the cognitive processing demands of walking, with a larger increase in reaction time to an auditory stimulus on the secondary task, when walking toward a small target than walking toward a large target. Reaction times also increase when a subject gets closer to the target, specifically when subjects are three steps from the target (Bardy \& Laurent, 1991).

In addition to task complexity, reaction times seem to vary according to age under various circumstances. Shumway-Cook \& Woollacott (2000) investigated the effects of cognitive tasks on postural stability in young and older adults. Subjects performed a choice reaction time task while maintaining quiet stance under six sensory conditions that manipulated the availability of accurate visual and somatosensory cues. The secondary reaction time task required subjects to identify an auditory tone as being "high" or "low". The addition of the reaction time task did not affect stability in young adults, but resulted in decreased stability in older adults when both visual and somatosensory cues were removed. A decrease in the ability to react quickly may reflect an age-related change in musculature. A recent study on obstacle avoidance under time pressure conducted by 
Weerdesteyn et al. (2007) has shown that older adults produce average onset muscular latencies (in response to an obstacle) $10 \mathrm{~ms}$ slower than the younger group while walking on a treadmill. Compared with younger subjects, the response amplitudes were smaller among older adults, and along with the delayed response, there was a significant association with obstacle avoidance success rates. Thus, the age-related decline in neuromuscular control could play a direct role in obstacle-related falls. In addition, older adults face a reduction in visual and kinesthetic sensitivity, which might affect their ability to perceive a given stimulus and produce an adequate response (Shumway-Cook \& Woollacott, 2001, p.231).

\subsection{Processing}

The accomplishment of any type of movement requires the processing of all sorts of information. High-level processing might be responsible for the management of information mentioned in the previous sections, such as the decoding of various sensory data.

It is important to refer to high-level processing as having an influence on motor control. The term cognitive does not necessarily mean conscious control (ShumwayCook \& Woollacott, 2001, p.165). The cognitive aspects are based on the adaptive and anticipatory roles that the central nervous system plays in the control of posture and balance. Adaptive postural control includes a modification of sensory and motor systems as a response to changing environments and tasks, whereas anticipation involves the preparation of sensory and motor systems for environmental demands based on past experiences. 
Occupying the highest level in information processing, the cortex is divided into sections, which are reflections of each of their functions. Most of the direct projections to the spinal cord originate from the primary and pre-motor cortices many also originate in the somatosensory cortex (Gazzaniga et al., 1998).

Spinal neuron activity can be regulated directly, as well as indirectly by the central nervous system. The direct connection is provided by the cortico-spinal tract, which is composed of neurons that originate in the cortex and terminate monosynaptically onto alpha motor neurons (Gazzaniga et al., 1998). This pathway is also known as the pyramidal tract, as it was initially thought of originating from the large pyramidal cells in the cortex. Now, we know that cells of different sizes, in several layers of the cortex have the capacity to sprout direct connections. Indirect connections are those that don't send information directly to the spinal cord via the pyramidal tract, but aim other brain structures like the brain stem nuclei, the basal ganglia, the cerebellum and even some cranial nerve endings.

Motor activity is controlled by two entities: the cortical motor system and the subcortical motor system. The cortical system, which is comprised of the primary motor cortex, the pre-motor cortex including supplementary motor areas, and the posterior parietal cortex, provides specific sources of information (Gazzaniga et al., 1998). The primary motor cortex is responsible for information that is used in the actual execution of movement, whereas the pre-motor cortex and the supplementary motor areas are mainly concerned with the planning and the sequencing of movements. The sensory information that is used to guide movement is assigned to the posterior parietal cortex, which works in close relation with the pre-motor area. 
Movement preparation is also partially controlled by the subcortical motor system, which includes both the cerebellum and the basal ganglia. These structures are considered as the fine tuners in movement because of their implication in complex movement timing and coordination (Shumway-Cook \& Woollacott, 2001, p.85). The three parts of the cerebellum are used as calibrating mechanisms for various areas of behavior. The vestibular cerebellum is used in the control of balance, as well as the coordination of eye movements with the body's movements (vestibulo-ocular reflex) and the spinocerebellum's functions ensure the smoothness of actions.

While these structures are essential in regulating current execution, the neocerebellum more important in planning, meaning that it helps to control voluntary movement (Gazzaniga et al., 1998). Specifically, it serves as a storage facility for internal models as well as efference copies. An efferent copy is a copy of an output signal that was sent from the central nervous system. The copy is stored in the neocerebellum and is used to generate the predicted sensory feedback (corollary discharge) of a motor command. The actual sensory consequences of the motor command are compared with corollary discharge to inform the central nervous system of external actions.

\subsection{Spatial memory and cognitive orientation}

Many aspects of daily living require internal representations of our environments, such as walking from the bedroom to the washroom in the dark for example.

Research questions in spatial cognition focus on how spatial knowledge is acquired, how such information is formatted into memory and how it is transformed during real and imagined movements of navigable spaces (Denis and Loomis, 2007). In 
addition, scientists are interested in the specificities of spatial cognition when it concerns either small-sized configurations, or the large-scale environments that surround people and constitute navigable spaces (Hegarty et al., 2006).

Böök \& Gärling (1980) proposed that orientation is maintained during locomotion by recurrent processing of information received through different sensory systems about the locomotor distances and the changes in direction. The relevant features of a locomotion path, such as distances and directions are encoded into short-term memory. The encoding of these variables into memory may only require a small amount of central processing (Lindberg \& Gärling, 1982). Sequential associations are formed between the features that are collected on a continuous basis during locomotion, which are already found in short-term memory (Moar and Carleton 1982).

Böök \& Gärling (1980) suggested that an additional task requiring central processing capacity carried out concurrently during locomotion interfered with that processing. Subjects were asked to estimate the direction and distance to the starting point of a walked linear path, which was out of sight, while counting backwards. Subjects who counted backwards during locomotion took more time to estimate distances and directions than subjects with no counting task.

Foley (1985) has argued that no response taken from a perception-action experiment can be taken as a "true" measure of perception, but that the goal in research on space perception is to develop a theory of perception. In his view, as long as the subject has had experience to develop a map between physical and perceived space, the subject can carry out visually directed action without systematic error. Loomis et al. (1992) present three hypotheses to explain how visually directed action could be accurate, despite that no consensus exists on the veridicality of perceived visual space. 
The first hypothesis is that subjects are able to perceive egocentric distance correctly and to use visually perceived distance to initiate walking. This results in the ability to walk without systematic distance error to the location of the target within a range of distances (up to $7 \mathrm{~m}$ ). According to the first hypothesis, the position of a moving subject is continuously updated with respect to the starting point, through the use of various sensory signals. The subject is then able to compute the direction and direct oneself towards a target, with a process called path integration (Israël et al., 1997).

A second hypothesis is that subjects are able to modify a response using a type of cognitive correction, and this corrective process does not necessarily use conscious thought. Specifically, it could include a detection of error during walking, such as seeing that you are about to fall short of a target and be able to use vision to correct your movement. It may reflect unconscious learning that allows the coordination of different responses.

A last possibility is that independent processes serve the conscious perception of space and motor control activity. In contrast to the second hypothesis, the same processes that are responsible for conscious visual perception are not involved in the control of action (Loomis et al., 1992). Research in visually guided action has indeed shown a degree of dissociation between the visually perceived direction of a target and the pointing direction of the hand toward the same target (Bridgeman \& Hoover, 2008).

\subsubsection{Path integration}

The sensory impulses that are generated by the displacement of a subject are also known as idiothetic signals, and consist of optical flow, proprioception, efference copies and inertial signals (Israël et al., 1997). Subjects can also estimate the traveled distance 
from self-generated information alone, for example without any external cue like vision or audition (Glasauer et al., 1994; Loomis et al., 1992; Thomson, 1983). Studies on path integration involving passive linear movement demonstrated that subjects were able to reproduce the distance as well as the velocity of an imposed passive motion, such as being pushed in a wheelchair (Berthoz et al., 1995).

Although models on path integration have been proposed (Benhamou \& Seguinot, 1995), the neural mechanisms involved in its process still have not been clarified (Israël et al., 1997). We do know, however, that spatial memory plays a key role in the internal coding of the distance and the direction of perceived motion (Israël et al., 1997). The path integration hypothesis is limited, because individuals performing goal-directed tasks are unable to reach exactly the location of a target when vision is absent (Rieser et al., 1990; Loomis et al., 1993).

\subsection{Cognition and aging}

During navigation without vision, the afferent information coming from the proprioceptive and vestibular systems contribute to the coding of spatial information. Encoding is impaired, however, in instances where one or many sensory inputs are unavailable due to aging (Day \& Cole, 2002).

Sensory deficits, as naturally experienced by older adults, are instances that challenge encoding. When there is disruption of either peripheral or central proprioceptive or vestibular pathways, older adults are less aware of the positions of the head, body and legs in space or even the position of the body itself. With a mild deficit, walking may not appear to be obviously abnormal if the person can see well. However, 
in locomotion without vision, staggering and unsteadiness may increase in aging individuals (Haywood \& Getchell, 2001).

As individuals get older, their ability to perform certain tasks (i.e. recover from an imbalance, navigate around obstacles at high speeds) may be less than their abilities at a younger age, but they are still able to function in normal situations when they can focus on the task. However, when they are required to perform multiple tasks at once, they may not be able to perform both tasks to the best of their ability (Shumway-Cook \& Woollacott, 2001, p.362). The exploration of how attentional capacities affect balance abilities in different situations is a popular field of study. If maintaining posture during locomotion does require attentional processing, does a change in sensory information due to aging demand more attention? Do older adults perform less well than younger adults under these circumstances?

Teasdale et al. (1993) studied the balance (center of pressure (COP)) of young and older adults who were sitting versus standing on a normal or foam surface, with either eyes open versus closed. The foam surface was used to decrease sway-related sensory information available for the control of balance. They also measured reaction time (RT) on a secondary task in which the subject pressed a button at the sound of an auditory cue. As sensory information decreased (foam surface) the postural task became increasingly difficult and RT was longer for both young and older adults, but the effect was significantly larger in older adults. It suggests that the amount of attention is related to the degree of instability in the task and that older adults required more attention to perform the postural task (Teasdale et al., 1993). 


\subsection{Motor system}

Three essential components characterize the motor system's contribution to locomotion: progression, stability and adaptation (Patla, 1991; Das \& McCollum, 1988). Progression is lead by motor programs, which ensures rhythmic muscular activations, such as the alternative limb movements during walking (Patla, 1991). A common definition of the motor program comes from Keele (1968). It says that a motor program is a "set of prestructured muscle commands that executes movement in the absence of peripheral feedback". Progression also requires the ability to initiate and terminate locomotion and to guide locomotion toward end points that are not necessarily visible (Shumway-Cook \& Woollacott, 2001, p.306). To increase stability during standing, the goal is to maintain the vertical projection of the body's center of gravity within the base of support. Dynamic stability entails counteracting the force of gravity, as well as expected and unexpected forces. The third essential requirement of locomotion is the ability to adapt gait to meet the goals of the individual and the demands of the environment (Shumway-Cook \& Woollacott, 2001, p.306). Successful interactions with the environment require that gait be modulated to avoid obstacles, negotiate uneven terrain and change speed and direction.

\subsection{Posture control}

Posture control for stability and orientation requires an interaction of musculoskeletal and neural systems (Shumway-Cook \& Woollacott, 2001, p.165). The musculoskeletal components include joint range of motion, spinal flexibility, muscle properties and a biomechanical relationship between body segments (kinematics). The neural components include neuromuscular response synergies, sensory processes such as 
the somatosensory, vestibular and visual systems as well as high-level processing needed for mapping sensation to action.

A number of factors contribute to posture control. Body alignment is the first, as it enables us to minimize the effect of gravity on the body, which tends to pull us off center. Muscle tone then prevents the body from collapsing from the influence of gravity, by utilizing inputs from the somatosensory system. For instance, the activation of cutaneous inputs on the soles of the feet results in pressing the foot toward the support surface, thus increasing postural tone in associated extensor muscles (Shumway-Cook \& Woollacott, 2001, p.168). Inputs from the visual and vestibular system are also used to maintain posture, by altering the distribution of postural tone in the neck muscles and limbs that is activated by a change in head position.

Standing balance is achieved in early childhood; it is therefore safe to say that it is one of the most fundamental human movements, especially since balance is an important prerequisite in the attainment of upright bipedal locomotion (Haywood \& Getchell, 2001).

\subsection{Gait}

The initiation of gait is a destabilizing event by which the vertical projection of the centre of gravity is forced forward and outside the support base (Shumway-Cook \& Woollacott, 2001). The only stabilizing period is during the double-support stance and even then, one of the feet is pushing off with significant force while the other is accepting the full weight of the body (Winter, 1980).

Humans normally use a symmetrical alternating gait pattern because it provides the greatest dynamic stability for bipedal gait (Raibert, 1986). Therefore, normal 
locomotion can be described as having a symmetrical gait pattern, where one limb initiates a step cycle just as the opposite limb reaches the midpoint in its cycle (Shumway-Cook \& Woollacott, 2001, p.308). Normal and abnormal gait patterns are also described with temporal and distance parameters, including velocity, step length, step frequency and stride length. Although walking speeds vary among individuals, selfselected speeds tend to stay within a small range of rates, with the goal of optimizing energy expenditure (Ortega et al., 2008). As speed is increased, the proportion of time that is spent in the stance phase is reduced, which in turn lessens stability.

Another way of describing the gait cycle is through its kinematics, that is the movement of the joints and segments of the body (Shumway-Cook \& Woollacott, 2001, p.310). When viewed from a sideways perspective, a person who is walking seems to move along a series of horizontal and vertical oscillations, which is the result of angular movements of the lower segments of the body, including those of the hip, knee and ankle (Winter, 1980). These angular movements are also accompanied by the rotation and tilting of the pelvis when a foot is stepping forward. Knee flexions are observed during stance, contributing to flatten the vertical movement of the center of mass and during the swing phase to allow the foot to clear the ground (Shumway-Cook \& Woollacott, 2001, p.310). Ankle motion also makes an important contribution to smooth gait. Flexion of the ankle during stance increases smoothness from step to step.

The control of other variables involved in walking is also important, like the dynamic balance of the head, arms and trunk as well as toe clearance during the swing phase (Winter et al., 1990). 


\subsection{Posture control, gait and aging}

Age-related effects on the motor system that control posture and gait mainly involve a decline in muscular function. This is caused by changes in muscle fiber quantity and qualitative changes in skeletal muscle structure (Yu et al., 2007). Lower limb muscle weakness correlates with poor performance on tests of balance, abnormal gait patterns and reduced general mobility (Sturnieks et al., 2008).

Muscle mass diminishes considerably between the ages of 20 and 80 years and is mostly due to atrophy and loss of individual muscle fibers, which seems to be preferential of fast-twitch fibers (Sturnieks et al., 2008). The mechanisms underlying qualitative changes are complex, and may include changes in the turnover rate of contractile proteins, as well as the modification of these proteins by oxidative stress (Harper et al., 2004). The specific functions that deteriorate as a result of these losses include a decline in the velocity of contractions, the maximum isometric and isotonic forces and an increase in muscle fatigue (Haywood \& Getchell, 2001). This directly influences the ability of an older individual to recover quickly from balance disturbances.

Muscle strength and endurance also affect standing posture especially when it is accompanied by a reduction in bone density. Osteoporosis, which is present in 1 in 3 women and 1 in 5 men over 50 years of age influences spinal flexibility and range of motion (Kanis, 1994). These factors lead to a stooped posture and affect the optimal alignment of the spine (Shumway-Cook \& Woollacott, 2001, p.229). Figure 7 is a representation of the changes in the spine that occur with age.

Gender-related differences are also observed in muscle function of older adults (Yu et al., 2007). In this study, men were found to have larger muscle fibers than women. Furthermore, women had slower maximum velocities of muscle shortening, 
meaning that women took longer to produce a muscle contraction. The gender-related difference in muscle contraction has been suggested to contribute to the more severe frailty and impairment in old women than in old men (Yu et al., 2007). Although the exact mechanisms of observed gender-related differences are unknown, it has been suggested that altered hormonal influences (e.g. oestrogen) in women may be involved (Phillips et al., 1993).

The changes in gait patterns in the elderly are observed on the basic components of gait and the variability with which they present themselves: stride length, cadence and velocity (Sturnieks et al., 2008). Older adults tend to walk with slower velocity, shorter step length, wider step width and a relatively increased proportion of time spent in the double-support phase.

The kinematic changes in older people include a reduced range of motion in the hip, knee and ankle, as well as a reduced angular velocity of the lower trunk, increased anterior pelvic tilt, increased mechanical energy expenditure and a larger toe-out angle (Sturnieks et al., 2008).

According to Winter et al. (1990), there is an increasing need to document the motor pattern changes that occur in the gait of the elderly, and to determine whether or not those changes are related to balance deficits and declined performance in mobility. 


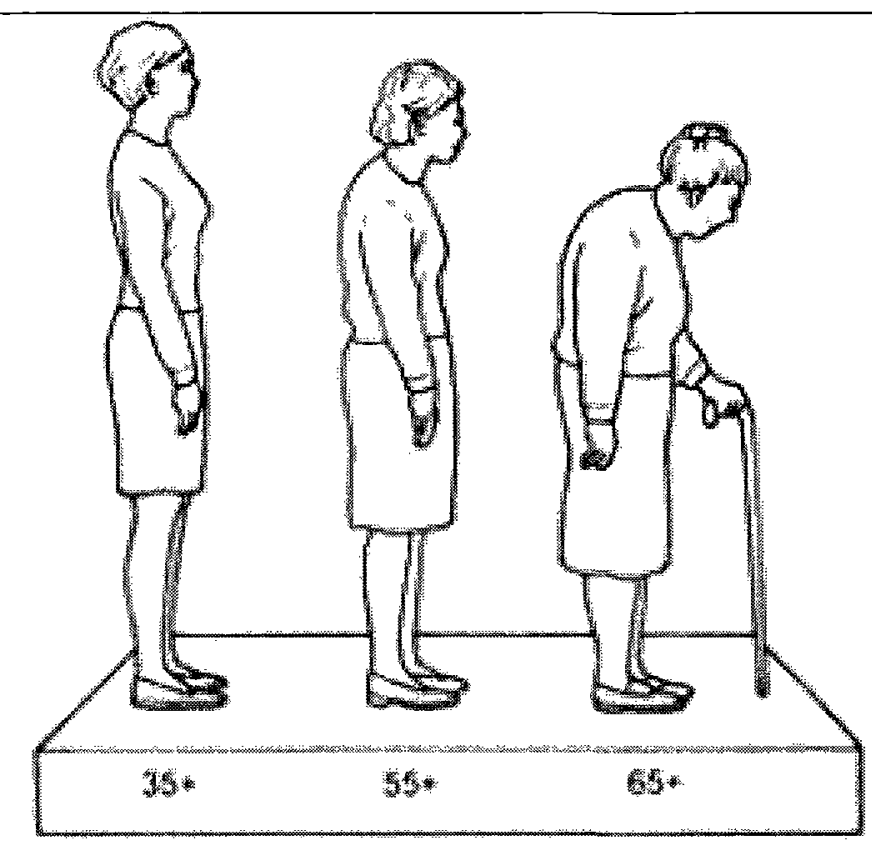

Figure 6: A comparison of postural alignment across a period of thirty years. Changes in spinal flexibility can lead to a stooped posture among elderly people (National Osteoporosis Foundation, 2009).

Movement control is achieved through the cooperative involvement of many structures. For instance, sensory inputs are involved in many functions. In the somatosensory system, muscle spindles, Golgi tendon organs, joint receptors and cutaneous receptors contribute to spinal reflex control, moderate spinal pattern generator output, modulate descending commands and contribute to the perception and control of movement through ascending pathways. Vision allows a person to identify objects in space and determine their movement (exteroceptive sensation), as well as give us information about where our body is in space, the relation of one body part to another and the motion of our body (visual proprioception). The vestibular system is sensitive to two types of information: the position of the head in space and head accelerations. 
As sensory information ascends to higher levels of processing, every level of the hierarchy can modulate the information coming into it from below, allowing higher centers selectively tune the information coming from lower centers. Information coming from the sensory receptors is continually processed as it ascends the neural hierarchy, enabling meaningful interpretation of the information. In the association cortices there is a transition from perception to action. The parietal lobe participates in processes involving attention to the position and manipulation of objects and of the body in space. The motor cortex interacts with sensory processing areas and with the basal ganglia and cerebellar areas to identify where we want to move, to plan the movement and to execute our actions.

Changes in movement control reflect the ability of a person to integrate postural control into a locomotor pattern (Shumway-Cook \& Woollacott, 2001). When evaluating gait patterns of older people, consideration must be given to the underlying mechanisms contributing to these changes. Older adults take more time to monitor the visual environment (Haywood \& Getchell, 2001) and to alter an upcoming step to avoid an obstacle. Changes in the characteristics of gait in older adults are influenced by balance ability, leg muscle strength, and changes in the availability of sensory information. Cognitive factors, such as fear of falling and attentional problems may also be important contributors. 
5.0 Research on navigation

The ability to reach a previously seen target while blindfolded has been investigated experimentally, using both short and long distances (Elliott, 1987; Fukusima et al., 1997; Paquet et al., 2007; Paquet et al., 2008; Rieser et al., 1990; Steenuis \& Goodale, 1985; Thomson, 1983).

Over greater distances (between 6-21 meters), Thomson (1983) reported that the subjects' accuracy was impaired, more so than over short distances (0-6 meters). Specifically, Thomson found that variable error, which is the inconsistency of results (Schmidt \& Wrisberg, 2004), increased abruptly as a function of distance. This increase was observed at a distance of approximately 9 meters. Other studies (Elliott, 1987; Rieser et al., 1990; Steenuis and Goodale, 1985; Loomis et al., 1987) have failed to replicate Thomson's findings.

Perhaps accuracy does change over long distances, as proposed by Rieser et al. (1990). In this particular study, the methods were closely modeled to those of Thomson (1983). Adult subjects were requested to view eleven targets set between 2-22 meters, and walk towards them without vision. The variable error did increase linearly with distance, but with a small average of $8 \%$ of the target distance. The average error or constant error was negligible, ranging from $0-7 \%$ of the target distance. The accuracy of these blind navigation performance results, over such a distance, seems noteworthy.

Nevertheless, walking without vision is still a difficult task among young adults, because it requires several capabilities, such as sensing the environment, route planning and the execution of movement (Glasauer et al., 1994). 


\subsection{Young adults}

In the mid 1980's Thompson $(1983,1986)$ and Elliot $(1986,1987)$ preformed very similar experiments with opposing results. In 1983 Thompson set out to find out whether locomotion could be accurately controlled when there is no visual input during the locomotion. Thomson asked young subjects to view targets ranging from $3-21 \mathrm{~m}$, close their eyes and walk to them. After conducting three different experiments it was concluded that subjects were able to locate targets with considerable accuracy, while blindfolded, as long as the time it took to reach their target was less than eight seconds. If reaching a target required more then eight seconds, accuracy of the subjects went down significantly. The measure of accuracy was the variability of how far the subject was from the target (maximum 9 meters).

Elliot (1986) decided to adopt Thompson's (1983) methodology in an attempt to replicate his results. In Elliot's experiment subjects walked to 5 different distances in three different conditions, with a delay of 0,2 or 4 seconds after seeing the target and before walking. Each condition had five trials. Subjects also had 3 practice trials to each of the targets before starting the trials. One major difference in Elliot's (1986) experiment from Thompson's (1983) original design was that on these practice trials subjects received no feedback.

Contrary to Thompson's (1983) findings, Elliot (1986) did not find any greater variability in walking error results for subjects reaching the target before or after Thompson's (1983) 8 seconds rule. Instead, Elliot (1986) found that variability in walking error only increased when distance increased. A second experiment was then conducted, which included a full visual condition, to provide support that continuous visual input is important for locomotion control. This experiment found once again that 
variability in walking error only increased with the distance required to get to the target. Furthermore, it was found that all subjects in the visual condition preformed consistently better then subjects in the non-visual condition. From these results Elliot (1986) concluded, contrary to Thompson (1983), that continuous visual input is required for an individual to accurately control movement.

In that same year, Thomson sent a quick rebuttal to Elliot (1986) in an attempt to justify his experiment. In this rebuttal Thompson's (1986) major argument was that Elliot (1986) did not give feedback to participants during practice trials, which affected participants' walking speed and therefore violated the eight-second rule. Thompson (1986) believed that this changed Elliot's (1986) findings significantly. Therefore, in 1987 Elliot set out to disprove Thompson (1983) once and for all.

Elliot's (1987) new experiment included a non-feedback and a feedback practice group, walking either slow or fast over 3 distances and with 3 different time delays. Once again Elliot (1987) was unable to replicate Thompson's (1983) results, with the new results being consistent with his previous study in 1986. There was no rebuttal this time. Elliot (1987) however was left with one mystery unsolved. It was found that the number of practice trials received in the 1987 experiment compared to the earlier 1986 experiment decreased the tendency to undershoot the target. Elliot (1987) was unable to explain this observation.

A study by Laurent \& Thomson (1988) investigated the ability of young adults (23-45) to walk towards a target that was located at 9 meters away from a start line, under various visual and target displacement conditions. During the target displacement conditions, subjects were asked to walk regularly, with shortened paces or with longer paces. The four visual conditions included normal vision, vision restricted to a 
"snapshot" when the foot which was instructed to land on the target was on the ground, a "snapshot" when the desired foot was in swing phase and no vision after departure. Their results show that subjects succeed in reaching the target in most cases. It was suggested that continuous visual guidance is not necessary; the timing of the visual information is more important than the total amount of information that is available.

Rieser et al. (1990) assessed the ability of young adults to navigate accurately without vision towards a series of previously seen targets without any feedback. Three walking conditions were tested: standard walking, time delay and fast walking. The 11 different targets were located between 4-24 meters. Variable errors were small and linearly related to target distance, averaging at about $8 \%$ of the target distance. Unlike Thomson's (1983) findings, Rieser et al. (1990) did not observe a substantial increase in variable error at around 9 meters.

Mittelstaedt \& Mittelstaedt (2001) conducted an experiment similar in design to that of Rieser et al. (1990) with subjects walking towards 11 different targets located between 2 and 21 meters. As testing was conducted in a hallway, an experimenter kept a firm hold on the subjects shoulder to prevent from veering into the wall. The means of velocity, step length and step rate were calculated by counting the number of steps taken in a certain amount of time over the distance traveled. To prevent direct feedback, the subject was led away from the final position before being allowed to remove the blindfold.

Their results indicate that path length estimation varies as a function of walking velocity, step length and step rate. When subjects walked towards the target at a standard velocity the performance was fairly accurate. However, when walking at a slower speed, subjects behaved as if they underestimated the path length and consequently walked 
further, whereas at faster velocities they behaved as if they slightly overestimated and consequently walked a shorter distance.

A study by Paquet et al. (2008) also examined blind navigation in young adults during forward and sideways walking, but included a concurrent task. By using a cognitive task (counting backwards) they wanted to see if sideways walking would require more attentional resources than forward walking. Subjects were asked to perform a navigation task alone, as well as a dual-task condition. There was also a condition where subjects were sitting while counting backwards, which helped determine the attentional demand of the counting by itself. They found that the rate of counting backwards was significantly reduced in the dual-task compared with the sitting. However, there were no significant changes in navigation measures between the navigation alone and the dual-task. Such measures included traveled distance, angular deviation and body rotation. It was suggested by the authors that subjects had used a task prioritization strategy, which explains the performance of the primary task was not affected during the dual-task condition.

Allen et al (2004) investigated the ability of young and older adults to walk without vision towards a series of points of origin (ranging from 1-4,3 m) in three separate conditions. In their distance to target task, they found that young subjects were overshooting at shorter distances but were undershooting in longer distances. In the turn to target task, subjects were rotating a bit more than what was required of them to reach the $1-\mathrm{m}$ target. At 6 target angles between $120^{\circ}$ and $150^{\circ}$, young subjects were deviating from the target angles at an average of $6^{\circ}$. In young adults, the mode of locomotion did not have an effect on return distance walked and very little on angle turned toward the point of origin in the triangular task. 
Sparrow et al. (2002) investigated the attention demands of walking in young and older adults using a dual-task paradigm, and used reaction times as the secondary task. Two gait tasks were used, where the first was an "unconstrained walking" in which participants would walk the 8 meter walkway at a comfortable speed, and a targeting task where they were requested to place either foot between target strips that were fixed at the end of the walkway. Walking speed was the navigation measure that was used to assess differences between conditions. Baseline walking speed was measured during both gait conditions without having a secondary task. In young adults, they found no significant differences or interactions for walking speed between the walking and targeting task and between the baseline and dual-task. The result of their investigations in older adults is discussed in the following section.

\subsection{Older adults}

In the distance-to-target task, Allen et al. (2004) found that their older adults did not differ significantly from the young adults when being led on foot. In contrast, older adults' performance was impaired after they were brought along the route segments in a wheelchair and then asked to execute the same route while walking. This task limited them primarily to vestibular information. Both groups were overshooting the target at distances of 2 and 2,6 meters but were undershooting the target during the longer distances of 2,$8 ; 3,4 ; 3,6$ and 4,3 meters. In the turn to target task, older subjects were rotating a bit more than younger adults. The shorter distances were accurately walked in older adults, but they had significant problems in walking the proper distance when distances were longer. Specifically, older adults were undershooting the target by a margin that increased when distances increased. 
In older subjects, Sparrow et al. (2002) found results that were similar to those of young adults in terms of walking speed; there were no significant differences or interactions in walking speed between the unconstrained walking and targeting task and between the baseline walking and dual-task. As well, there were no significant differences in walking speeds between young and older adults.

\subsection{Research on reaction times}

Many studies have examined attentional demands of walking in a dual-task paradigm (Lajoie et al., 1993; Sparrow et al., 2002; Lajoie et al., 1996; Teasdale et al., 1993). Lajoie et al. (1993) evaluated the attentional demands of young adults during static and dynamic equilibrium tasks. Reaction times were used to measure the demand in attention during sitting, standing with a broad base of support, standing with a narrow base of support (feet together) and during walking along an 8-meter pathway. They found that standing and walking required more attention than sitting and that the demand for walking was greater than for standing.

Another study by Lajoie et al. (1996) investigated attentional demands in upright stance and gait in young and older adults. Auditory stimulus was delivered during these static posture conditions: sitting, standing with a broad base of support (shoulder width) and standing with a normal base of support (feet together), and during the single and double support phases of walking. They found a significant effect of group and task, as well as a group by task interaction. For both groups, reaction times were shorter in the sitting than the standing and walking tasks and older adults produced significantly longer reaction times than young adults.

In Teasdale et al. (1993), young and older adults were asked to respond to an 
unexpected auditory stimulus using a hand-held button while standing feet together on a force plate and examined reaction times during sitting and standing feet shoulder width apart as control conditions. Reaction times were then examined under several sensory conditions: vision with a normal surface and no vision on a foam surface. They found that both groups showed a delay in reaction times as task complexity increased. In addition, reaction times in older adults were longer in the absence of vision than in young adults.

Sparrow et al. (2002) investigated the attentional demands of walking in young and elderly adults while using a dual-task paradigm. For the secondary task, a visual and/or an auditory stimulus were presented to them with reaction time software that was activated when the subject stepped on a pressure-sensitive mat. Subjects would receive either a visual stimulus, an auditory stimulus or in some cases would receive both stimuli simultaneously and then have to press a hand-held button to record their response. Reaction times were recorded as a function of six $500 \mathrm{~ms}$ intervals from gait initiation. Baseline reaction times were taken while subjects were standing at the start line, before the start of a trial.

In young and older adults, reaction times increased in all of the conditions when compared with the no-walking baseline reaction times. When they compared reaction times between the walking tasks, they found that attention demands were greater in the targeting task than in the "unconstrained walking" task and visual reaction times were longer than for the auditory stimulus in the targeting task. It was suggested that this might be due to an interference associated with viewing both the stimulus and the target. The only difference that was observed between groups was that reaction times in the visual and auditory/visual condition were significantly longer in older than young adults, 
but not in the auditory alone condition. The results from the reaction time delay data (intervals) show a remarkable increase in attention demand at gait initiation (0-500 ms). The demand levels off for the remainder of the trials, but increase again slightly when subjects are approaching the target.

Similar results were found in another study (Bardy \& Laurent, 1991). The authors suggested that the elevated RTs at the beginning of the trials were due to the attentional cost of gait initiation. A reduction in attentional demand during steady walking is reflected by shorter RTs. This is followed by an increase in demand as an obstacle or target is approached.

7.0 In which direction is navigation research heading?

The results of these navigation studies have some disparate, and some common findings. Some researchers suggest that vision is not necessary to perform a distance to target task (Thomson, 1983), whereas others suggest that it is important, whether it is constant (Elliott, 1986) or crucial at certain instances (Laurent \& Thomson, 1988). The accuracy of performances may be variable according to certain time delays (Thomson, 1983), distances (Elliott, 1986; Allen et al., 2004; Sparrow et al., 2002), walking velocity (Mittelstaedt \& Mittelstaedt, 2001) and during instances of divided attention (Paquet et al., 2008).

The reaction time studies that were discussed show a few common findings. First, reaction times seem to be much longer in more complex tasks, such as during walking versus sitting (Lajoie et al., 1993; Lajoie et al., 1996), and standing on a normal base of support versus a less stable one (Teasdale et al., 1993). Second, studies that examined differences in young versus older adults have shown significant increases in reaction 
times in older adults than in young (Sparrow et al., 2002; Lajoie et al., 1996), and that older adults had more trouble reacting to a stimulus when it was visual than when it was auditory. These results suggest that older adults require more attentional resources to perform postural and walking tasks without vision, than young adults.

In view of previous studies, there is a developing trend in conducting experiments using a dual-task design. In navigation research, the focus seems to be on the ability of individuals to walk towards targets of various distances with and without vision, all the while looking at the amount of information processing these tasks require. Another common theme in current research is the comparison between different populations. In this present study, the design is based on a combination of previous methods (Thomson, 1983, Rieser et al., 1990; Paquet et al., 2008; Sparrow et al., 2002; Lajoie et al., 1993; Lajoie et al., 1996) and will examine the attentional demands of a goal-directed blind navigation task in young and older adults. 


\section{Chapter III}

Attentional demands during a goal-directed blind navigation task in young and older adults 


\subsection{Objectives}

The general purpose of the study is to explore how aging affects the performance of navigation without vision. Specifically, the impact of aging on the interaction between attention and navigation is investigated.

The first objective of this study is to determine the effects of aging on distance and direction errors during navigation without vision. The second objective is to establish whether distance and direction errors, as well as reaction time are changed during a dual task (navigation and a reaction time task) in each group. The third objective is to determine the effects of age on the attentional demands, measured with reaction times.

\subsection{Hypotheses}

The first hypothesis is that the group of older adults will produce greater distance errors than younger adults. As well, they will produce greater direction errors (angular deviation) and body rotation in comparison with the younger group. Secondly, the traveled distance, angular deviation and body rotation produced during the dual-task shall be greater than errors performed during the blind navigational task alone in both groups of subjects. Furthermore, reaction times during the dual-task condition shall be longer than those in the sitting condition in both groups. Reaction times shall be longer in older adults than in young adults. Finally, reaction times (attentional demand) should increase when subjects of both groups will be approaching the target. 


\subsection{Methods}

\subsection{Subjects}

A total of twenty-four subjects participated. Table 1 shows the descriptive statistics of the study population. Young adults were recruited at the School of Human Kinetics at the University of Ottawa. Community dwelling older adults were recruited from the Heron Road Community Centre, which offers exercise and art programs to active seniors.

\begin{tabular}{|c|c|c|c|c|}
\hline & \multicolumn{2}{|c|}{ Young adults } & \multicolumn{2}{c|}{ Older adults } \\
\hline & Mean & Standard deviation & Mean & Standard deviation \\
\hline Age (years) & 23,7 & 2,9 & 72,6 & 4,3 \\
\hline Height $(\mathrm{cm})$ & 168,9 & 7,9 & 163,4 & 9,0 \\
\hline Weight $(\mathrm{kg})$ & 68,5 & 14,2 & 70,1 & 11,7 \\
\hline & & & & \\
\hline Gender & Males & Females & Males & Females \\
\hline & 6 & 8 & 3 & 7 \\
\hline
\end{tabular}

Table 1: Descriptive statistics of participants

Subjects were included if they demonstrated good health and showed no pathological signs that would affect their control of balance and gait according to a health status questionnaire (Appendix 1). Exclusion criteria included disease or injury to the nervous system (Parkinson's, Huntington's, stroke, head trauma), cardiovascular event within twelve months prior to the study (heart attack), loss of sensation in the lower limbs and chronic back pain. Furthermore, subjects were included if they reported no unexplained falls within the past 12 months. A Mini-Mental State Examination (Appendix 2) developed by Folstein et al. (1975) assessed cognitive status. The inclusion criterion was a score of 26 or more on the scoring chart. All subjects scoring 25 points and under were excluded. 


\subsection{Material}

A pair of modified ski goggles was used to completely remove vision during the blind navigation task. An MP3 digital audio recorder was used to record the stimuli and the verbal responses of the subjects. Data obtained from the MP3 digital audio recordings were stored onto an IBM laptop computer.

Auditory stimulus, consisting of $1000 \mathrm{~Hz}, 50 \mathrm{msec}$ in length was emitted from a portable speaker device worn by an examiner accompanying the subject, in a pouch strapped around the waist. The subjects' response "top" to the stimulus was recorded using an MP3 digital voice-recording device, held by the same experimenter, who remained in close proximity to the subject at all times during trials.

The lateral (x) and the longitudinal distance $(y)$ in reference to the straight-line trajectory were measured in centimeters using a measuring tape and a one-meter ruler. The body rotation was measured in degrees using a protractor aligned with the angle of the floor mark.

\subsection{Procedure}

Young adults were tested in the aerobics studio at Montpetit Hall, University of Ottawa. Older adults were tested in the gymnasium at the Heron Road Community Centre. Both rooms were spacious, quiet and only occupied by the research team at the moment of testing.

In the first condition, subjects were blindfolded in a seated position and asked to deliver a verbal response ("top") to an auditory stimulus lasting $50 \mathrm{msec}$ of $1000 \mathrm{~Hz}$. The instruction was to respond as quickly as possible after the stimulus. Ten stimuli were 
delivered at the beginning (pre-experiment) and ten at the end of the walking trials (postexperiment).

For the second experimental condition, named 'navigation alone', subjects stood behind a starting line, facing a target clearly marked on the floor with pink adhesive tape at a distance of eight meters ahead of the starting line. The subject was asked to look at the target. After 5-10 seconds, at the experimenter's signal ("go"), the subject would put on the opaque goggles and walk towards the target at a comfortable pace. When the subject believed that he/she had arrived at the target, the subject stopped and positioned the feet together as to facilitate feet position marking on the floor. The marking procedure is detailed in section 3.4. At the end of each trial, the subject remained blindfolded, was seated in a wheelchair and was returned to the start line by an assistant. This was done to prevent the subject from knowing his/her final position relative to the target and correct the trajectory in subsequent trials. At the assistant's signal, the subject was asked to remove the goggles and stand behind the starting line for the next trial.

The third experimental condition, named 'dual-task', followed the same protocol of the second condition, only with the addition of a concurrent task. The subject was asked to verbally respond ("top") as quickly as possible in response to an auditory stimulus, while performing the blind navigational task. The instruction to the subject was that the navigational task was the primary task and the reaction time task was the secondary task. The 8-meter distance to the target was divided into four 2-meter intervals (Interval 1: 0-2 meters, interval 2: 2-4 meters, interval 3: 4-6 meters and interval 4:6-8 meters), which were indicated by small marks to the side of the walkway. Subjects were unaware of these marks as they were located away from the walkway, which were used to facilitate the delivery of auditory stimuli by the researcher. 
The auditory stimuli were delivered at one of four distance intervals during the navigation trial. A random sequence of stimulus delivery was determined beforehand, to ensure that subjects would not anticipate the stimulus and all subjects would receive the stimulus during the same intervals in each trial. Table 2 is a representation of the determined sequence. In addition, two trials without auditory stimulus (catch trials) were incorporated into the twenty trials with stimulus, in order to prevent the subjects from anticipating the stimuli (Schmidt, 1982).

All subjects followed the experimental protocol in the same order. The seated reaction time test (10 stimuli) was performed first. Then subjects performed five trials of the navigation task alone, followed by five trials of the dual-task. This alternation was done four times in young subjects, to obtain twenty trials of navigation alone and twenty trials of the dual-task. Older subjects could only perform half of the trials, because the blind navigation task proved to be very fatiguing to these individuals. At the end, a second seated reaction time test (10 stimuli) was conducted. 


\begin{tabular}{|c|c|c|c|c|}
\hline \multirow[t]{2}{*}{ Trials } & \multicolumn{4}{|c|}{ RT Intervals } \\
\hline & 1 & 2 & 3 & 4 \\
\hline 1 & & & $\mathrm{x}$ & $\mathrm{X}$ \\
\hline 2 & & $\mathrm{X}$ & $\mathrm{X}$ & \\
\hline 3 & $\mathrm{x}$ & & & $x$ \\
\hline 4 & $\mathrm{x}$ & & $\mathrm{X}$ & $\mathrm{x}$ \\
\hline 5 & & $\mathrm{X}$ & & $x$ \\
\hline 6 & & $\mathrm{X}$ & $\mathrm{X}$ & $\mathrm{X}$ \\
\hline 7 & \multicolumn{4}{|c|}{ Catch trial (no stimulus) } \\
\hline 8 & $\mathrm{x}$ & $\mathrm{X}$ & & \\
\hline 9 & $\mathrm{X}$ & & $\mathrm{X}$ & $\mathrm{X}$ \\
\hline 10 & & $\mathrm{X}$ & $\mathrm{X}$ & \\
\hline 11 & $\mathrm{x}$ & & $\mathrm{X}$ & $\mathrm{x}$ \\
\hline 12 & & $\mathrm{X}$ & $\mathrm{X}$ & \\
\hline 13 & $\mathrm{X}$ & & & $X$ \\
\hline 14 & $\mathrm{X}$ & & $\mathrm{X}$ & $\mathrm{X}$ \\
\hline 15 & & $\mathrm{X}$ & & $\mathrm{X}$ \\
\hline 16 & & $\mathrm{X}$ & $\mathrm{X}$ & $\mathrm{x}$ \\
\hline 17 & \multicolumn{4}{|c|}{ Catch trial (no stimulus) } \\
\hline 18 & $\mathrm{X}$ & $\mathrm{X}$ & & \\
\hline 19 & $\mathrm{X}$ & & $\mathrm{X}$ & $\mathrm{x}$ \\
\hline 20 & & $X$ & $x$ & \\
\hline
\end{tabular}

Table 2: Representation of the stimulus delivery during twenty trials of the dual-task in young and old subjects (who did the first ten trial only), with " $\mathrm{X}$ " representing an auditory cue during a specified interval. Trials number 7 and 17 were used as catch trials.

\subsection{Measures}

Reaction time was measured by identifying the time lapse in milliseconds between the beginning of the auditory stimulus and the beginning of the verbal response that was recorded on the digital recording device. This was done by visual inspection of the trace imported in the computer. The computer software shows a graph of the auditory signal. The start of the stimulus and the start of the response are easily identifiable from the graph shown in Figure 7. 


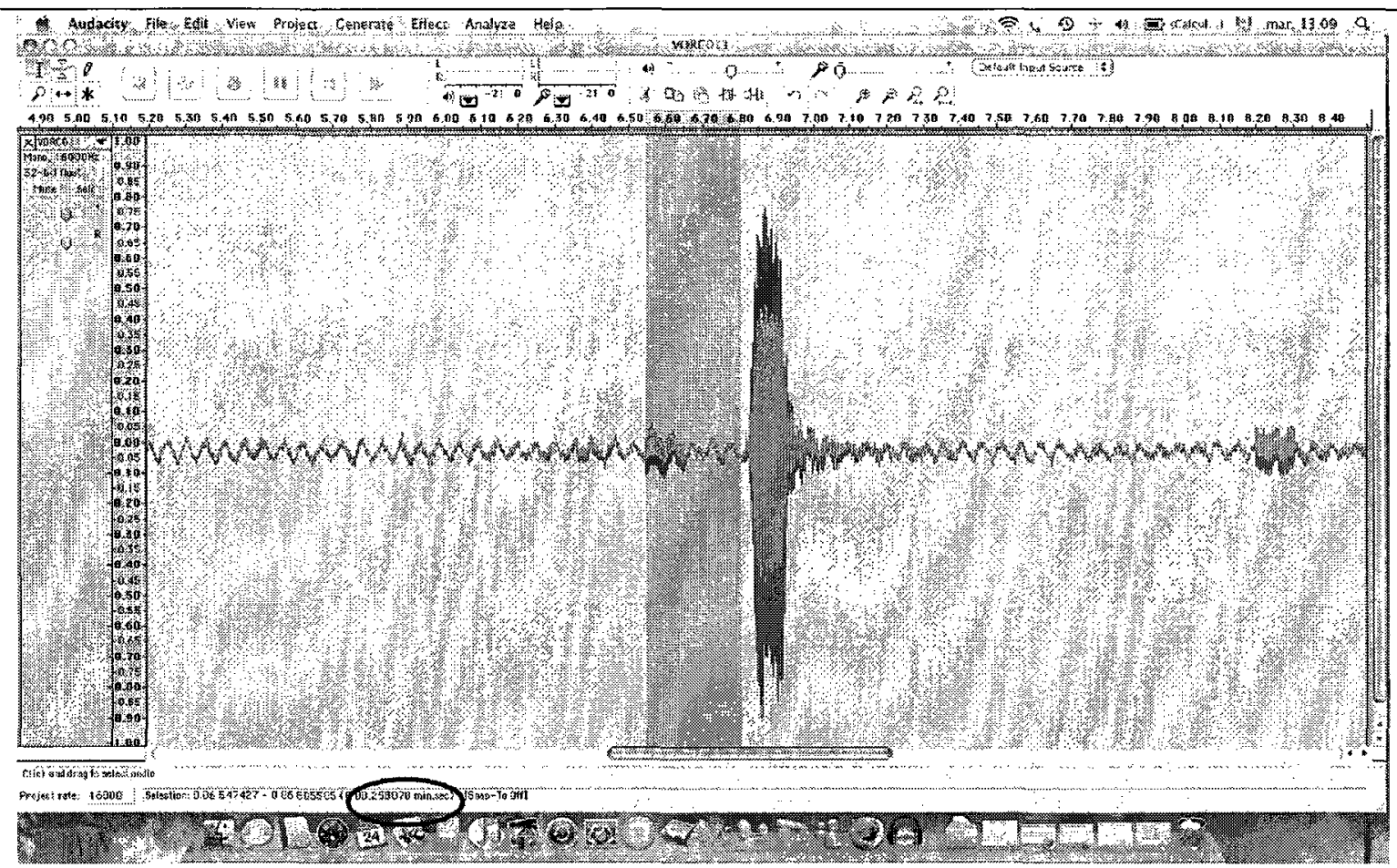

Figure 7: Screen shot of the software used to analyze the verbal response to the auditory stimulus. The sound waves of the stimulus and of the response are clearly seen, with the smaller portion being the short-duration stimulus and the larger amplitude being the verbal response. The vertical area shaded in grey represents the period in time (msec) between the beginnings of the response to the auditory cue, which is calculated by the program (circled on the bottom left). This particular trial shows a response time of 258 milliseconds.

Final feet positions were marked on the floor with coded clear adhesive tape. Subjects were required to bring both feet together at the end of the trial to facilitate the marking of the position with the adhesive tape at the tip of the toes, connecting the front of the subject's feet. A perpendicular mark on the tape indicated the location where the two feet were adjoined. These marks were made with clear adhesive tape, and were not visible to the subjects at the starting line. 
Figure 8 is an illustration of an aerial view of the experimental set-up and final feet position obtained from 8 trials. Wide bars represent the start line and target located eight meters away. Thin bars represent marks on the floor made of clear adhesive tape, coded by letter to identify the task and number of each trial. The letter " $\mathrm{C}$ " (for control trials) represents the navigation alone task, whereas " $R$ " represents the dual-task (navigation plus reaction time). Distance to the target in the $\mathrm{x}$-axis was given a plus $(+)$ sign if the mark was located on the right side of the target trajectory (dotted line) and a minus sign (-) when it is on the left. Distance in the $y$-axis is given a plus sign (+) if the mark was passed the target (overshoot) and a minus sign (-) if the subject did not reach the target (undershoot). 


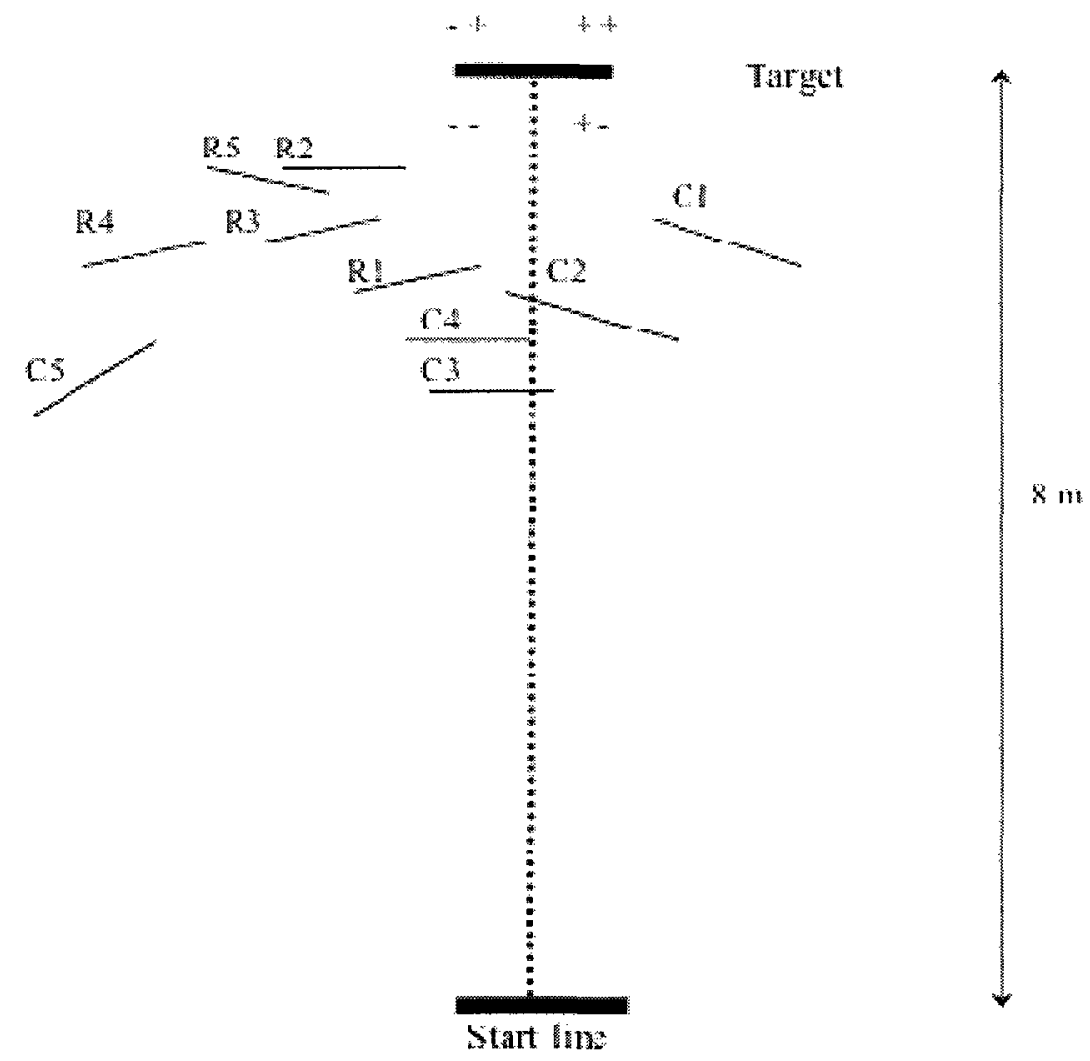

Figure 8: An aerial view of the experimental set-up and approximate final feet positions of young subject 11 , obtained from one block of 10 trials ( 5 of navigation only; 5 of dualtask). The dotted line is the straight-line trajectory of 8 meters from the start line to the target. With the exception of the first two trials of the navigation alone, which are indicated by ' $\mathrm{Cl}$ ' and ' $\mathrm{C} 2$ ', the distances for each mark were given a minus sign on the $\mathrm{x}$ axis and the y-axis. This indicates that the subject was consistently undershooting the target and was deviating to the left of the straight-line trajectory. 
Figure 9 illustrates how the distance and direction measures were obtained (Paquet et al., 2008). As shown in the diagram, the lateral error (X) was obtained by calculating the distance between the target and the final position of the subject's feet in the $\mathrm{x}$-axis. The longitudinal error $(\mathrm{Y})$ was obtained, by calculating the distance between the target and the final position on the y-axis. Distance traveled was calculated between the start line and the subject's final position as follows: Distance $(\mathrm{cm})=\mathrm{SQRT}\left[\mathrm{X}^{2}+\right.$ $\left.(\mathrm{Y}+800)^{2}\right]$.

The angular deviation (ADE) from the straight trajectory to the target was calculated as such: $\left.\operatorname{ADE}\left({ }^{\circ}\right)=\operatorname{ACRCTAN}[\mathrm{X} / \mathrm{Y}+800)\right]^{*} 100$. The angular deviation towards the right of the subject was considered as a positive deviation, and the left, a negative one. Body rotation was determined by measuring the angle of the floor mark (adhesive tape) with a protractor by using the orientation of the target as a reference ( 0 degrees). Clockwise rotation was considered as a positive rotation and counterclockwise rotation, a negative one. 


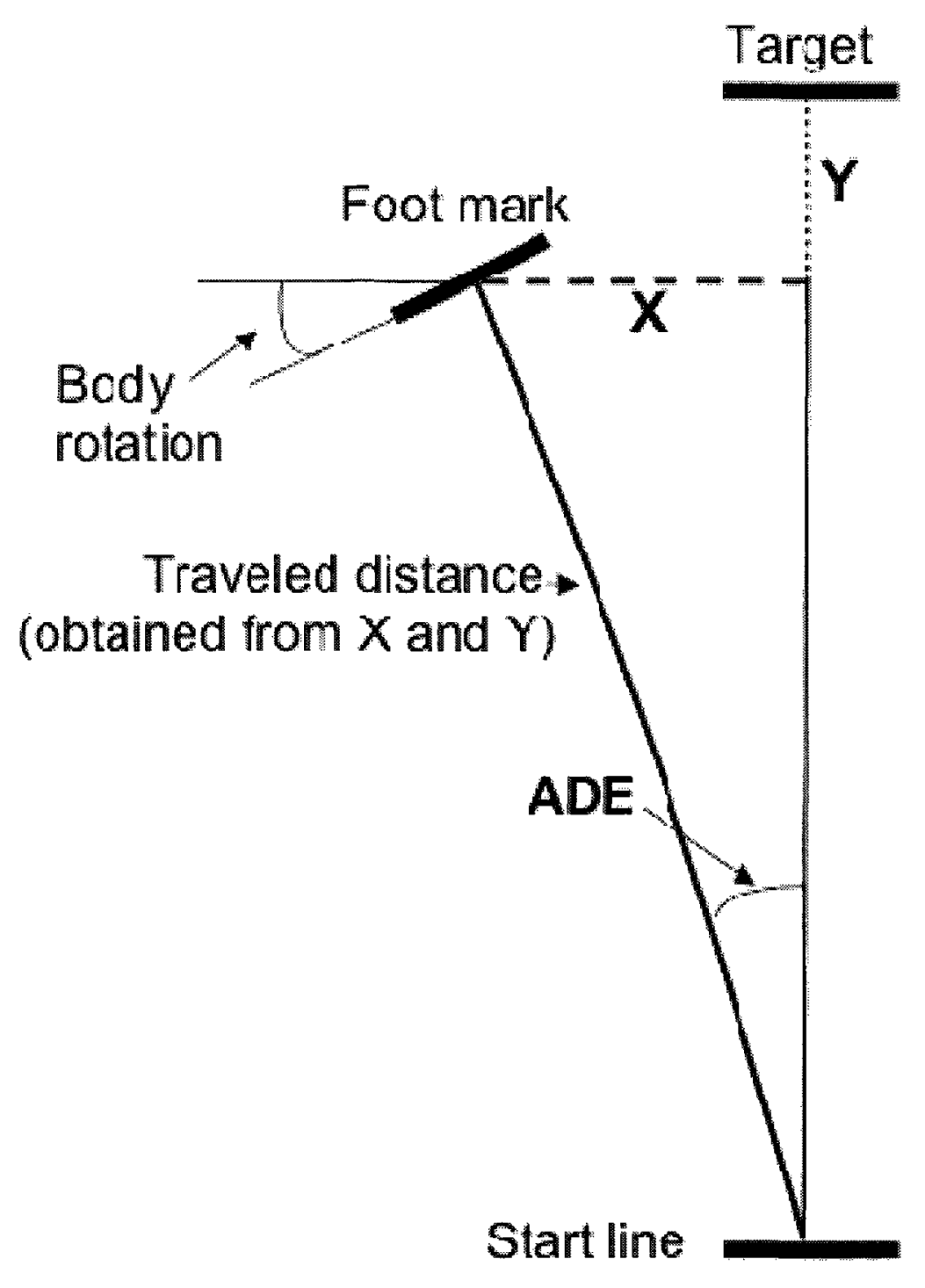

Figure 9: Illustrations of the start line, a target (located at $800 \mathrm{~cm}$ from the start line) and a footmark. $\mathrm{X}$ and $\mathrm{Y}$ coordinates are shown, as well as angular deviation (ADE) and body rotation. In this example, $\mathrm{X}$ and $\mathrm{Y}$ values would be negative (Paquet et al., 2008). 
4.0 Statistical analysis

Three two-way ANOVAs were performed. They compared the traveled distance, angular deviation and body rotation measures obtained during the two navigation conditions (navigation alone vs. the dual-task) for the two groups of subjects (young and older adults). A three-way repeated measure ANOVA compared reaction times obtained during the two conditions (seated vs. the dual-task) for the two groups (young and older adults). Furthermore, reaction times from the dual-task were separated according to the corresponding intervals in which they were recorded, in order to establish any differences in RTs between intervals. RTs in each interval were also compared with the sitting RTs. Post hoc (Tukey) analyses were used to determine the location of the differences when the ANOVA revealed significant differences with a $\mathrm{p}$ value smaller or equal to 0,05 .

\subsection{Results}

In all three variables of navigation measures, there were significant effects of age. However, there were no significant effects of condition on variables, with the exception of traveled distance. Conversely, reaction time results showed a significant main effect of condition, but no significant effects of age. Furthermore, significant differences were found in reaction times between the intervals. 


\subsection{Navigation measures}

Table 3 demonstrates the results from the two-way analysis on the traveled distance for the two groups and the two experimental conditions.

\begin{tabular}{llllll}
\hline $\begin{array}{l}\text { Sources of } \\
\text { variability }\end{array}$ & $\begin{array}{l}\text { Sum of } \\
\text { squares }\end{array}$ & $\mathbf{d F}$ & $\begin{array}{l}\text { Mean } \\
\text { square }\end{array}$ & F & Sig. \\
\hline $\begin{array}{l}\text { Condition } \\
\text { (nav. vs. dt) }\end{array}$ & 42777,296 & 1 & 426777,296 & 27,123 &, $000^{*}$ \\
\hline $\begin{array}{l}\text { Group } \\
\text { (young vs. old) }\end{array}$ & 1541201,07 & 1 & 1541201,07 & 97,948 &, $000^{*}$ \\
\hline $\begin{array}{l}\text { Condition } \mathrm{x} \\
\text { group }\end{array}$ &, 000 & 0 &. &. &. \\
\hline
\end{tabular}

Table 3: Two-way ANOVA results of the effect of Condition (navigation alone (nav.) vs. dual-task (dt)) and Group (young vs. old) on traveled distance (cm). There was a significant main effect of Condition, a significant effect of Group and no significant interaction.

Traveled distances were significantly shorter during the navigation alone than during dual-task and the traveled distance was significantly shorter in young than old subjects. However, there was no Group and Condition interaction. Figure 10 illustrates the traveled distance between the two groups during the two conditions. 


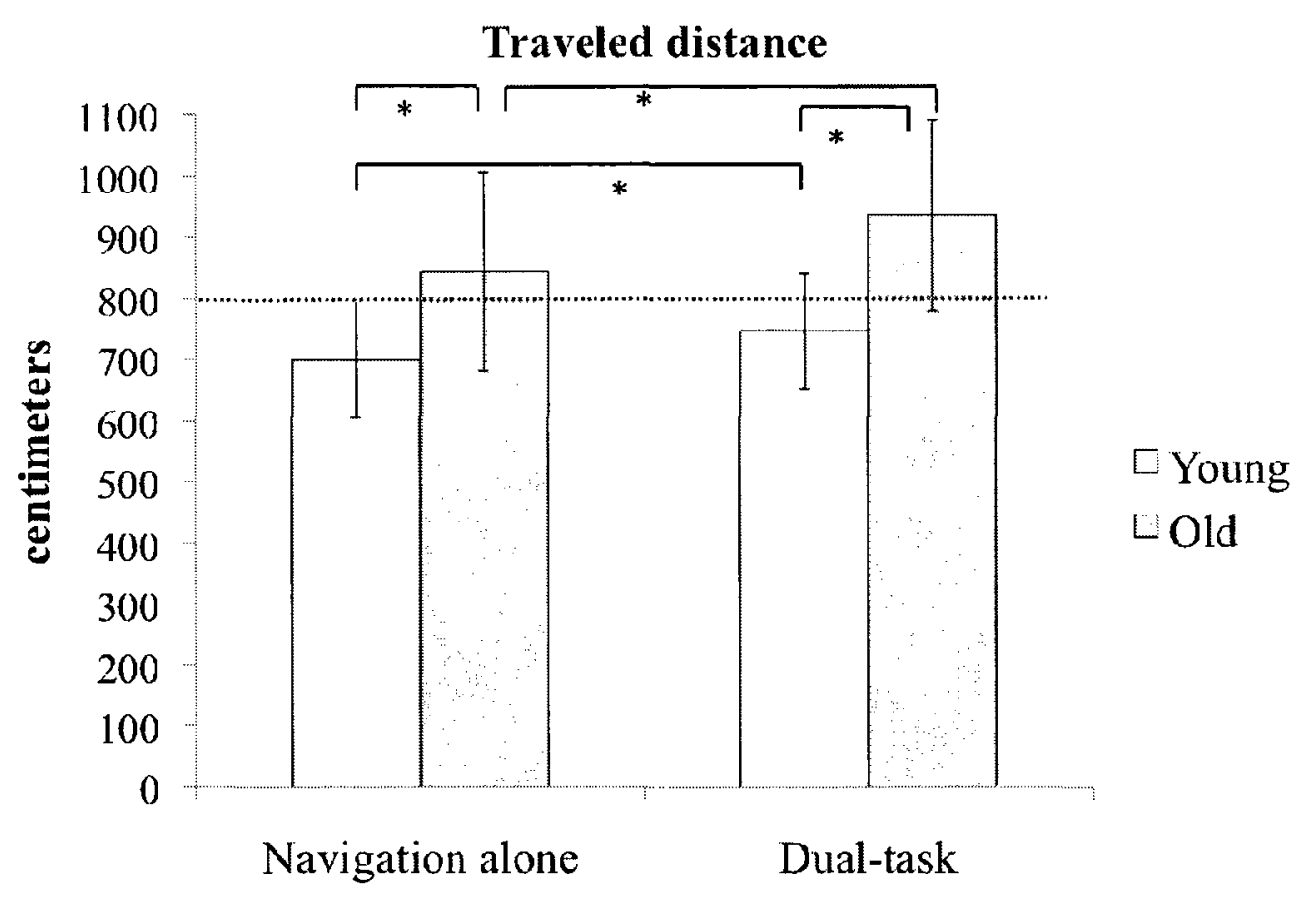

Figure 10: Means \pm SD of traveled distance $(\mathrm{cm})$ of young and older adults during the navigation alone and the dual-task. A significant main effect of task and age were found, ${ }^{*} \mathrm{p}<0,01$. The target was located at $800 \mathrm{~cm}$ from the start line.

Young subjects undershot the target (traveled distance less than $800 \mathrm{~cm}$ ), while older adults overshot it (traveled distance longer than $800 \mathrm{~cm}$ ).

Table 4 shows the results of the two-way ANOVA on the angular deviation for the two groups during both experimental conditions. 


\begin{tabular}{llllll}
\hline $\begin{array}{l}\text { Sources of } \\
\text { variability }\end{array}$ & $\begin{array}{l}\text { Sum of } \\
\text { squares }\end{array}$ & dF & $\begin{array}{l}\text { Mean } \\
\text { square }\end{array}$ & F & Sig. \\
\hline $\begin{array}{l}\text { Condition } \\
\text { (nav. vs. dt) }\end{array}$ &, 004 & 1 &, 004 &, 516 &, 473 \\
\hline $\begin{array}{l}\text { Group } \\
\text { (young vs. old) }\end{array}$ &, 183 & 1 &, 183 & 24,843 &, $000^{*}$ \\
\hline $\begin{array}{l}\text { Condition } \mathrm{x} \\
\text { group }\end{array}$ &, 000 & 0 &. &. &. \\
\hline
\end{tabular}

Table 4: Two-way ANOVA results on the effect of Condition (navigation alone vs. dualtask) and Group (young vs. old) on angular deviation (degrees). There was a significant main effect of Group, no significant effect of Condition and no significant interaction between Group and Condition.

Older adults had larger angular deviations than young adults in both conditions. Angular deviations were not significantly different between the two navigation conditions and the interaction was also found not significant. Figure 11 shows the results of the angular deviation for both groups and conditions. 


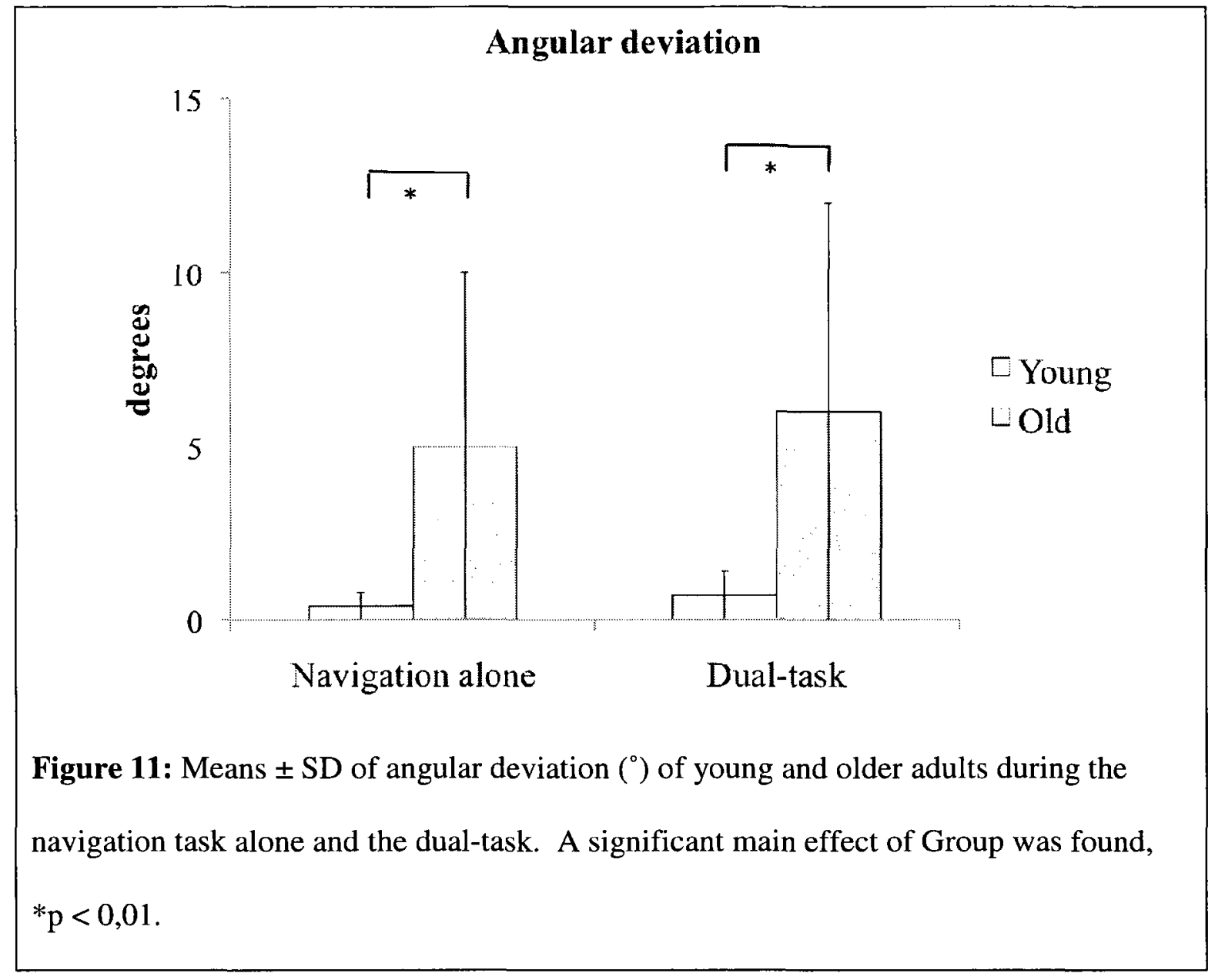


Table 5 shows the results of the ANOVA on body rotation for the two groups during the two experimental conditions.

\begin{tabular}{llllll}
\hline $\begin{array}{l}\text { Sources of } \\
\text { variability }\end{array}$ & $\begin{array}{l}\text { Sum of } \\
\text { squares }\end{array}$ & dF & $\begin{array}{l}\text { Mean } \\
\text { square }\end{array}$ & F & Sig. \\
\hline $\begin{array}{l}\text { Condition } \\
\text { (nav. vs. dt) }\end{array}$ & 59,405 & 1 & 17780,303 & 171,132 &, $000^{*}$ \\
\hline $\begin{array}{l}\text { Group } \\
\text { young vs. old) }\end{array}$ & 4489,518 & 1 & 4489,518 & 43,211 &, $000^{*}$ \\
\hline $\begin{array}{l}\text { Condition } x \\
\text { group }\end{array}$ &, 000 & 0 &. &. &. \\
\hline
\end{tabular}

Table 5: Two-way ANOVA results on the effect of Condition (navigation alone vs. dualtask) and Group (young vs. old) on body rotation (degrees). There was a significant main effect of Group and Condition on body rotation.

Body rotation results were similar to those of the angular deviation with older adults having larger body rotations than young adults in the two conditions, but no effect of Condition. No interaction was found between Group and Condition. Figure 12 illustrates the significant difference in body rotation between groups. 


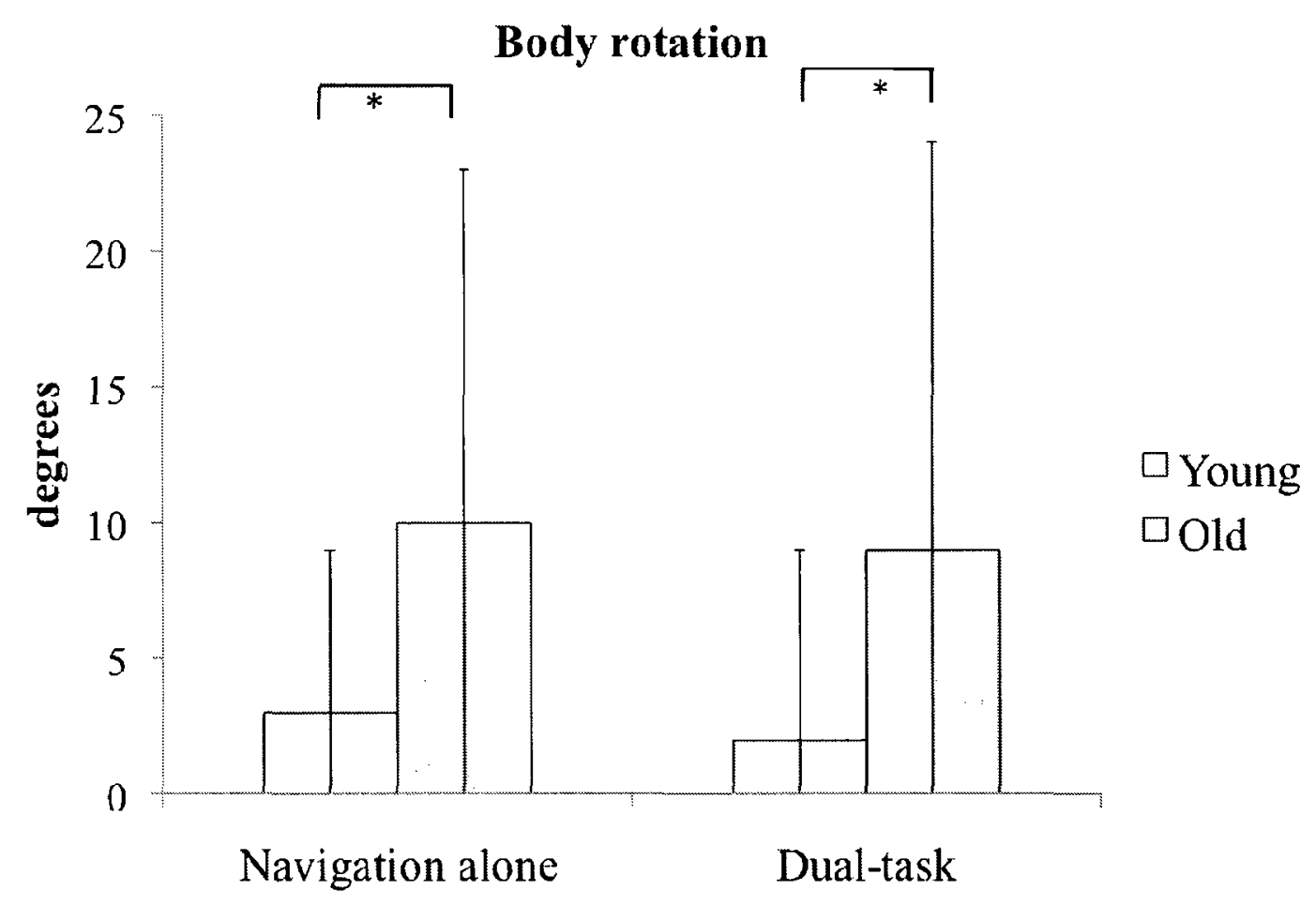

Figure 12: Means \pm SD of body rotation $\left({ }^{\circ}\right)$ in young and older adults during the navigation alone and the dual-task. A significant main effect of Group was found on body rotation, ${ }^{*} \mathrm{p}<0,01$. 


\subsection{Reaction times}

Table 6 shows the results of the ANOVA on reaction times for the two groups during sitting and the dual-task conditions.

\begin{tabular}{|c|c|c|c|c|c|}
\hline $\begin{array}{l}\text { Sources of } \\
\text { variability }\end{array}$ & $\begin{array}{l}\text { Sum of } \\
\text { squares }\end{array}$ & $\mathbf{d F}$ & $\begin{array}{l}\text { Mean } \\
\text { square }\end{array}$ & $\mathbf{F}$ & Sig. \\
\hline $\begin{array}{l}\text { Condition } \\
\text { (nav. vs. dt) }\end{array}$ & 161,576 & 4 & 40,394 & 21.51 &, $000 *$ \\
\hline $\begin{array}{l}\text { Group } \\
\text { (young vs. old) }\end{array}$ & 75,706 & 1 & 75,705 & 3.024 &, 096 \\
\hline Condition $\mathrm{x}$ group & 35,712 & 4 & 8,928 & 34.75 & $.0016^{*}$ \\
\hline
\end{tabular}

Results show a significant effect of Condition and a significant interaction of Group and Condition. After decomposing the interaction into its simple effects it was shown that for both groups, the reaction time in the sitting condition was significantly shorter than the reaction time in the navigation condition $(\mathrm{p}<0,05)$. In young adults, the sitting was significantly different than reaction times in all four intervals, but for older adults, the reaction times in the sitting condition were only significantly different than reaction times in intervals 1,2 and 4 . There were also significant group differences in reaction times between the intervals. Mean reaction times for both groups are illustrated in Figure 13. 


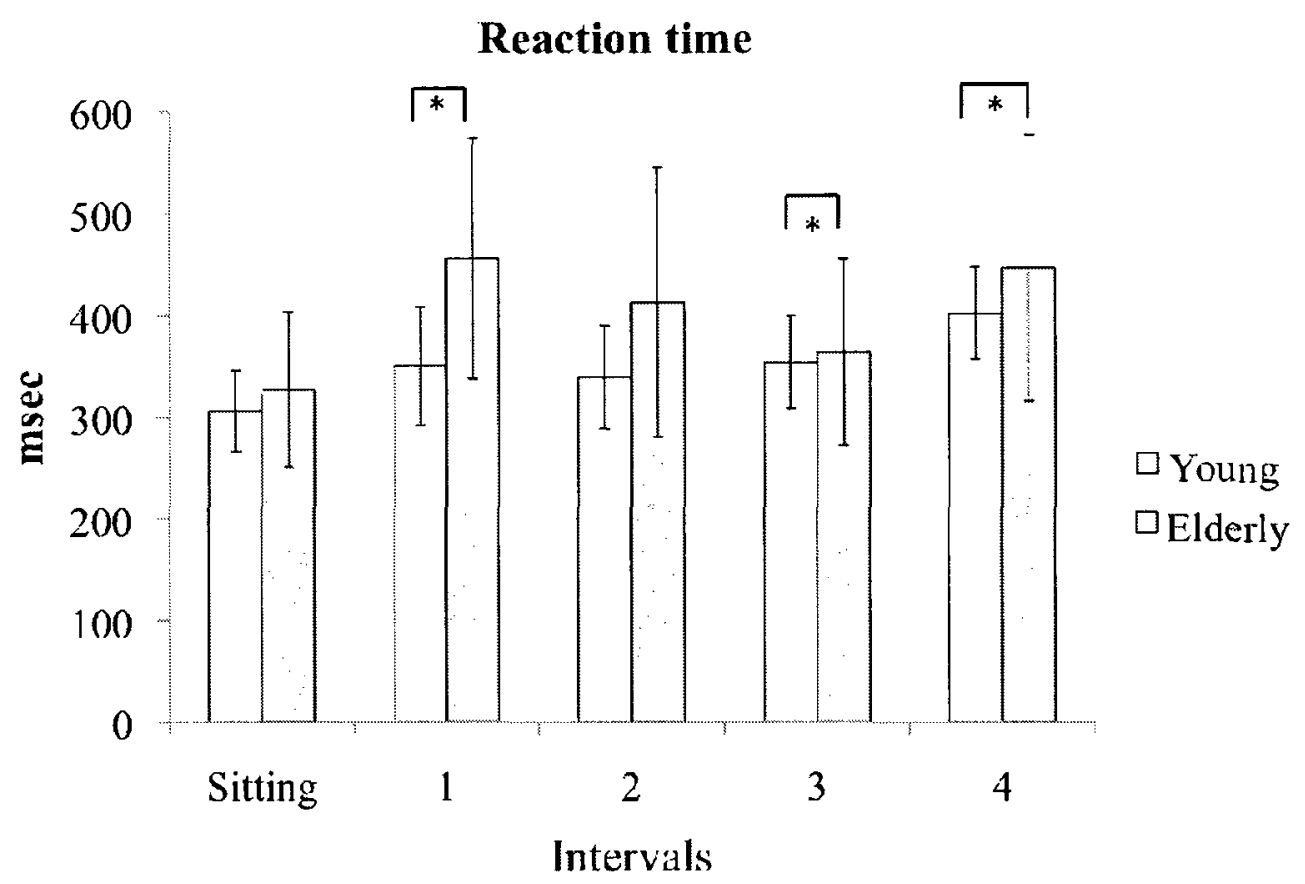

Figure 13: Means \pm SD of reaction times (msec) in young and older adults during sitting and during dual-task intervals $(1=0-2 \mathrm{~m} ; 2=2-4 \mathrm{~m} ; 3=4-6 \mathrm{~m} ; 4=6-8 \mathrm{~m}) . \mathrm{A}$ significant difference was found between groups in the first, second and fourth interval, ${ }^{*} \mathrm{p}<0,05$.

In young subjects, the reaction times of the last interval of the navigation task in young subjects were significantly longer than the reaction times in all other conditions (p $<0,05)$. Mean reaction time results for young subjects are illustrated in Figure 14. 


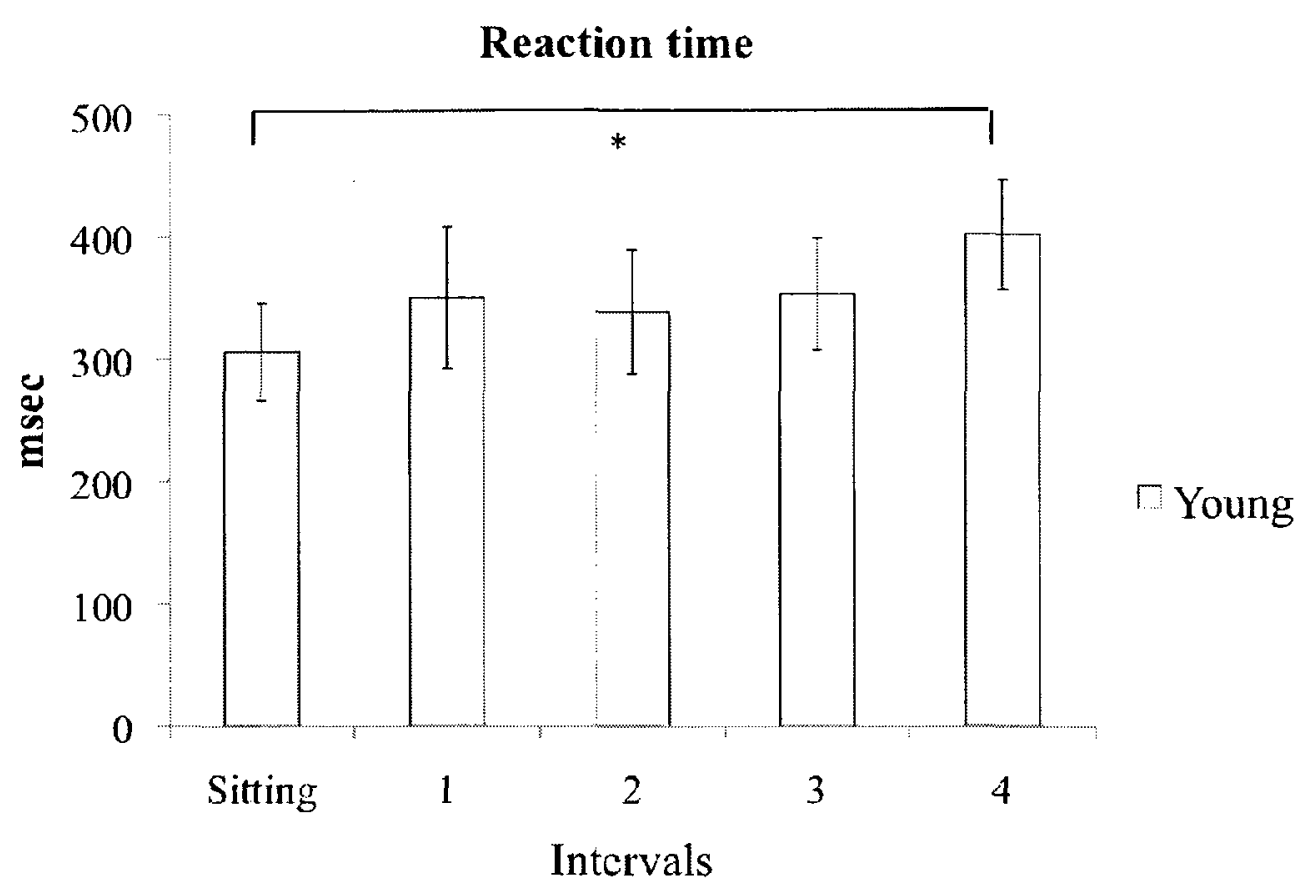

Figure 14: Means \pm SD of reaction times $(\mathrm{msec})$ in young adults during sitting and during dual-task intervals $(1=0-2 \mathrm{~m} ; 2=2-4 \mathrm{~m} ; 3=4-6 \mathrm{~m} ; 4=6-8 \mathrm{~m})$. A significant difference was found between reaction times in the fourth interval and those of all other intervals and in the sitting condition, ${ }^{*} \mathrm{p}<0,05$.

As for the older adults, the reaction times in the first interval were significantly longer than the reaction times in the second and third intervals. Furthermore, the reaction times in the fourth interval were significantly longer than in the second and third intervals $(\mathrm{p}<0,05)$. However, there were no significant differences between the first and the fourth intervals. Mean reaction time results for older adults are illustrated in Figure 15. 


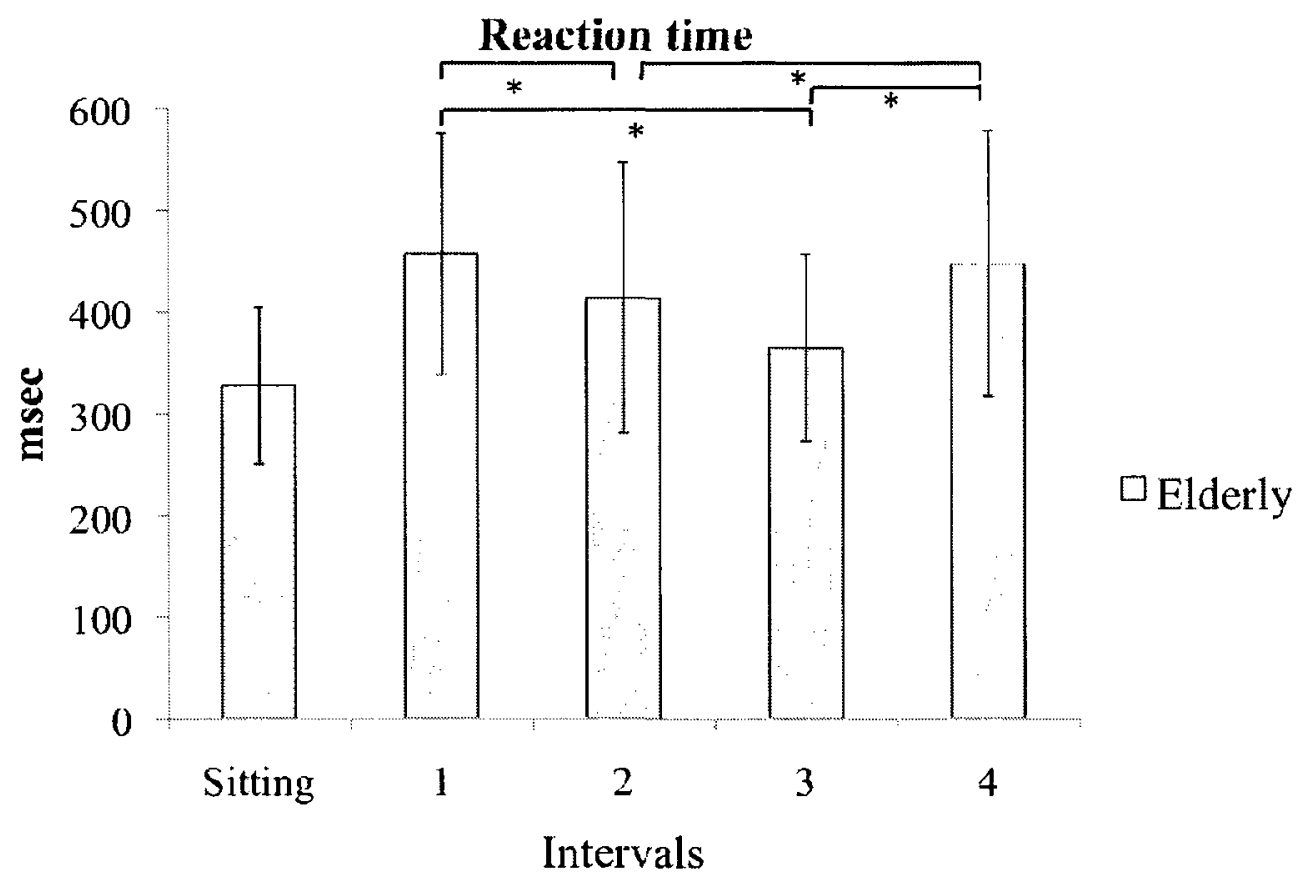

Figure 15: Means \pm SD of reaction times $(\mathrm{msec})$ in older adults during sitting and during dual-task intervals $(1=0-2 \mathrm{~m} ; 2=2-4 \mathrm{~m} ; 3=4-6 \mathrm{~m} ; 4=6-8 \mathrm{~m})$. A significant difference was found between reaction times between the first, second and third intervals, as well as between the reaction times in the fourth interval and the second and third intervals, * $\mathrm{p}<$ 0,05 . 


\subsection{Discussion}

6.1 Navigation and reaction times

The purpose of the first part of this discussion will be to outline the major findings in this study, and consider the reliability of the effects of the experiment by comparing them with published studies of walking without vision and studies examining attentional demands in young and older adults in dual-task paradigms.

\subsubsection{Traveled distance}

In addition to the differences between groups in the total amount of centimeters traveled, we observed a difference in the location of the ending points in relation to the target between groups. Specifically, we noticed that the majority of young subjects were undershooting the target and that older subjects were consistently overshooting the target.

A study on young adults performing a similar task found comparable results in terms of undershooting (Laurent \& Thomson, 1988). It was suggested that subjects undershot the target because it was located only a few meters from a wall, which may have prompted subjects to adopt a "play safe strategy". However, Laurent et al. (1988) found that when experimenting in an open area where subjects were walking to a 9-meter target, they were also undershooting. The space in which our subjects were tested could not have induced the effect of this strategy because it was large enough to accommodate large overshooting.

There has been evidence of an effect of walking velocity on path length during blind navigation studies in young adults (Thomson, 1983; Elliot, 1987; Rieser et al., 1990), but only by comparing standard with faster velocities. In a study conducted by Mittelstaedt \& Mittelstaedt, (2001) however, faster and slower velocities were examined. 
It was observed that subjects underestimated the path length at slower velocity and consequently walked further, whereas they overestimated it at faster velocity and walked a shorter distance. Young adults have been shown to walk faster than older subjects (Guérin-Lajoie et al., 2006), and this is what was observed in this study as well.

While taking into account the natural changes in posture control and gait patterns that occur with aging, including velocity, it is plausible that our older subjects were overshooting because they were intimidated by the task and were walking at a naturally slower pace than young adults. However, it is impossible to say for certain whether it is the reason for the overshooting, because gait parameters were not measured.

It is also interesting to note that when young subjects were distracted in the dualtask condition, they got closer to the target. Even if there was a bigger difference in traveled distance between navigation conditions, young subjects became more accurate in the dual-task. Such was not the case in older subjects. In contrast to young subjects, the older adults were consistently overshooting the mark, which was increased in the dualtask condition.

\subsubsection{Angular deviation and body rotation}

Angular deviation and body rotation were not significantly different between the navigation conditions, which is consistent with previous findings of blind navigation studies (Rieser et al., 1990; Paquet et al., 2007; Paquet et al., 2008). Without a significant change in direction parameters in the dual-task compared to the navigation alone, it is possible that subjects adopted a task prioritization strategy (Paquet et al., 2008). Subjects were in fact instructed to consider the navigation towards the target as the primary task, and the cognitive task as the secondary task. However, we are 
reminded that there was a significant effect of task on traveled distance. If task prioritization were indeed the strategy that was adopted by both subject groups, wouldn't all navigation variables be affected in the same way? If so, task prioritization is an unlikely explanation.

Conversely, is it possible that movement-related information coming from the sensory system is better at detecting rotations than linear displacement? It is widely known that the vestibular system relays information on rotation and accelerations/decelerations, but if subjects are walking at a constant speed, other sensory modalities must be recruited to supply the distance information. Together, vestibular and somatosensory information must be integrated and processed in such a way as to produce a clear cognitive representation of the environment and the location of the body within it (Israël et al., 1997). Perhaps the amount of cognitive resources needed to perform the integration and interpretation of information exceeds functional capacity when performing complex tasks (Shumway-Cook \& Woollacott, 2001, p.362).

Even if there were no significant differences in angular deviation and body rotation between conditions, there was however a significant difference found between groups, with older subjects having more trouble in maintaining a straight-line trajectory towards the target. A group studying perceived self-motion in a virtual environment also found differences between young and older adults in terms of veering (Berard et al., 2007). It was suggested that older adults had more difficulty maintaining a straight-line trajectory than younger adults because of altered sensorimotor integration or because of higher discrimination thresholds of optic flow. 
Allen et al (2004) investigated the ability of young and older adults to walk without vision towards a series of points of origin (ranging from 1-4,3 m) in three separate conditions. In the turn to target task, older subjects rotated more than younger adults. At 6 different target angles between $120^{\circ}$ and $150^{\circ}$, older adults deviated from the target angles an average of $12^{\circ}$, twice the average deviation of young adults. It was suggested that an age-related deficit in the encoding of body rotation information from the vestibular system leads to a decline in the accuracy of path integration, which is consistent with our previous assumption. The age-related differences in path integration performance are related to cognitive resources, including speed of processing and working memory. These resources mainly reflect the ability to retain information temporarily while attention is switched from one task to another (Allen et al., 2004). An age-related decline in the ability to retain and retrieve information when performing a concurrent task may explain the differences seen here between groups.

\subsubsection{Reaction times}

Significant differences were observed in this study when we compared reaction times that were collected during the sitting task and those that were collected during the dual-task condition. Similar results were found when comparing reaction times from tasks differing in complexity (Lajoie et al., 1993; Lajoie et al., 1996; Teasdale et al., 1993; Sparrow et al., 2002). Most of these studies compare reaction times in a sitting task with either a standing task with various support conditions (e.g.. feet positions, support surfaces) or a walking task, with or without a target. All studies used an auditory cue as a stimulus, and one study (Sparrow et al., 2002) employed an additional visual stimulus. 
During a targeting task, attention demands were higher than during unconstrained walking (Sparrow et al., 2002), as they were also when balance requirements increased (Lajoie et al., 1993). It was suggested that increasingly complex actions require a higher level of cognitive resources, and is reflected in the significant difference in reaction times (Lajoie et al., 1993; Teasdale et al., 1993).

The significant differences in reaction times during the four dual-task intervals of this present study are similar to those of other studies (Bardy \& Laurent, 1991; Sparrow et al., 2002). There was a significant increase in attentional demand when our young subjects were approaching the target (fourth interval). Bardy \& Laurent (1991) and Sparrow et al. (2002) report elevated RTs when subjects were approaching targets as well. Furthermore, a significant difference between RTs in the first and other intervals was observed in this study, which these authors have also reported. It was suggested that the increase in RTs during the first delay interval (0-500 ms in Sparrow et al., 2002) was due to an increase in attentional cost at gait initiation.

Significant differences were also found in these studies between young and older adults in terms of reaction times, which were also found in this present study during the dual-task condition only. Some of these findings proposed that older adults are more affected by a reduction in base of support than young adults (Lajoie et al., 1996) and that in conditions without vision, postural control requires more attentional resources in older than young adults (Teasdale et al., 1993).

There was also a difference between groups during the first interval (gait initiation). According to Sparrow et al. (2002), alterations in locomotor dynamics that occur in aging individuals may provide an explanation for the increase in attentional requirements observed during gait initiation. In this case, increased attention may 
compensate for age-related declines in sensory and cognitive processes (Shumway-Cook et al., 1997).

Sparrow et al. (2002) also found significantly longer reaction times between older and young adults, depending on the type of stimulus. Older adults' reaction times in the visual, but not in the auditory condition were significantly longer than for the young group in both walking tasks. Reaction times for young and older adults were not different in no-walking baseline trials. It seems that older adults were more perturbed when presented with a visual stimulus during a walking task than when presented with an auditory cue. Only auditory cues were used in this study and all of our subjects were blindfolded. It is possible that our particular group of subjects did not find the auditory stimulus as perturbing as was expected, and might explain for the lack of difference in reaction times between groups during the dual-task condition.

During testing, it was observed that in some instances subjects were not responding to the auditory cue at all during the dual-task condition, or were not using the correct word in responding, which was more apparent in the older group. Is it because subjects were so focused on the targeting task that they were not paying attention to the stimulus, or is it due to a hearing impairment? The former is more likely than the latter, despite that subjects were elderly and that auditory acuity does decline significantly with age (Haywood \& Getchell, 2001). Although hearing ability was not quantified during our study, none of the subjects reported having hearing impairments and none were wearing hearing aids. Furthermore, there were no instances where subjects did not respond to the auditory cue when performing the sitting test.

The findings of all these navigation and reaction time studies suggest that in everyday gait tasks, increased attention demands would reduce the resources available for 
other (secondary tasks). The high visual reaction time associated with the targeting task in the Sparrow et al. (2002) study, for example, has serious safety implications, such as for road crossings. In demanding gait tasks, competing sensory information (e.g. visual, auditory) associated with a secondary stimulus could either lead to declines in gait task performance, increasing the risk of a fall. Alternatively, allocation of increased attentional resources to the gait task may reduce the response time to a hazard.

\subsection{Impact of aging on navigation and reaction times}

Significant differences were found in results between performances of young and older adults, with the older group traveling a farther distance, producing larger angular deviations and body rotations. The differences between groups could be due to the changes in the sensory, motor and cognitive systems that occur with aging. The purpose of the second part of the discussion is to consider what age-related effects on the systems might account for the performance results of this study.

As discussed in sections 2.1 .3 and 2.2.1, sensory deficiencies that contribute to navigation errors in older adults may include the degeneration of vision, a reduction in peripheral sensation and a decrease in vestibular function (Shumway-Cook \& Woollacott, 2001, p.235). The age-related changes associated to the proprioceptors (somatosensory and vestibular systems), can include a reduction in tactile sensitivity, a decline in joint position sense (Haywood \& Getchell, 2001) and disturbed vestibular reflexes due to a loss of hair and nerve cells (Rosenhall \& Rubin, 1975). When there is a decline of visual perception with age, individuals are not as accurate in determining the scale of their

actions (Haywood \& Getchell, 2001). Combined with a decline in proprioceptive information, older adults are not as precise when attempting to determine their position in 
relation to that scale, and are more likely to produce larger errors, which is what was found in this present study.

Age-related effects on the motor system mainly involve a change in gait patterns, a decline in balance control (Sturnieks et al., 2008), as well as muscular strength (Yu et al., 2007). Winter et al. (1990) found that older adults, in comparison to young subjects, significantly reduce their walking velocity and step length, spend more time in a doublesupport phase and had a flatter foot landing, possibly to increase stability during movement. The increase in navigation error that was demonstrated by older adults in this present study could have been due to the time spent while walking. Even though velocity was not measured, it was observed by experimenters that older adults did walk slower than young subjects. An increase in walking time would suggest that older adults would have spent more cognitive resources to remember the target that was perceived at the beginning of the trial. Even if there is no decrease in knowledge, aging brings problems of access to stored information (Craik \& Bialystok, 2006).

A reduction in walking speed, as mentioned above, is a way to increase postural stability during locomotion. The maintenance of a stable upright posture is a complex process and age-related changes have been proposed at every stage (Woollacott \& Shumway-Cook, 2002). In terms of input, there is the deterioration of the peripheral sensory processes, which was described above. In respect to output, there is a slowing of peripheral nerve conduction velocity and a decrease in muscle strength. Standing balance in older adults is particularly impaired when visual inputs are removed (Teasdale et al., 1993). Muscle mass will also have an influence in the output phase of balance control and locomotion in older adults. Lower limb weakness and a decrease in muscular endurance is especially debilitating in women, who experience a greater decline in 
maximum contraction force and in contraction velocity, making it even more challenging for older women to react quickly to a hazard (Yu et al., 2007).

Combined with the absence of vision in our protocol, older adults face a bigger challenge than younger adults to perceive where their bodies are in relation to the target. Older adults may try to compensate for these shortcomings by allotting a larger amount of attentional resources than would be necessary in young adults to complete the same task. This may explain why older adults would not notice the auditory cue or forget to respond.

There is increasing interest in the literature in developing performance-based tests to assess mobility in older adults, in order to predict outcomes such as falls and disability (Verghese et al., 2007). The walking while talking (WWT) test has been used in gerontology as an applicable test of divided attention to examine cognitive-motor interactions in everyday life (Verghese et al., 2007). WWT requires the ability to divide and switch attention between two tasks. Older adults may show a preference for preserving gait over talking during the WWT test (Woollacott \& Shumway-Cook, 2002), but not all studies report instructions specific to task prioritization during the WWT. In this present study task prioritization was specified. It may be possible that older adults were prioritizing as instructed, but that the level of attentional resources that was necessary to conduct both tasks simultaneously was exceeding their capabilities.

To see if the cognitive resource measures accounted for age-related variance in distance error, Allen et al. (2004) used a regression analysis. The variables in this analysis included age, sex, education, biological events, digit symbol, operation span, signed direction error and signed distance error. They found that the distance component produced a reliable correlation with age. Specifically, distance error accounted for $71 \%$ 
of the age-related variance. The results involving cognitive correlates indicated that agerelated differences in navigation performance were related to cognitive resources, specifically "speed of processing and working memory capability". Glass et al. (2000) also reported larger dual-task costs in older adults and concluded that the observed agerelated performance deficit had three sources: general slowing, process-specific slowing and the use of a more cautious task coordination strategy. This last component would help, again, to explain why older subjects were walking slower during the navigation without vision.

\subsection{Limitations and future considerations}

Despite having recruited enough subjects to achieve our desired statistical power, we believe that our sample size was still small and the number of subjects per group (young $\mathrm{n}=14$; older $\mathrm{n}=10$ ) was not equal. Furthermore, older adults could only complete half the number of trials that were required of the young subjects, which is another limitation. Older subjects found that the dual-task was quite fatiguing, despite being given some time to rest between trials (60-120 seconds maximum). It was important to experimenters that subjects would not perform if exhausted, as much as for their personal safety than for the quality of the data. Age differences in the older group could have made a difference in results as well. Even though $60 \%$ of subjects fell into the originally desired range of 65-75 years, there was a large difference in age between the youngest (62 years) and the oldest ( 80 years) subject and changes, both physical and cognitive, occur quickly in older populations. 
A large cross-sectional study by Baltes \& Lindenberger (1997) investigated the relationship between measures of sensory function (vision and hearing) and intelligence (perceptual speed, reasoning, memory, knowledge, fluency and composite). They found that vision and hearing accounted for $11 \%$ of variance in the younger group (25-69 years) and $31 \%$ in the older group (70-103 years). It was suggested that an increase in the ageassociated link between sensory and intellectual functioning might reflect an "age-based acceleration of changes in the nervous system". Older participants in this present study fall into both categories, as we had two subjects under the age of 70 and the others were over. Thus, it might be possible that a wide age range might reflect a wide range of cognitive abilities and explain the large standard deviations that were observed.

The structure of our trial blocks may also have been a limitation in this study, because we used 8 blocks of 5 trials, and each block consisted of either 5 trials of the navigation alone or 5 dual-task trials. There was an alteration between blocks, so that after 5 trials of navigation alone, the subject would perform 5 dual-task trials, and so on. This is what is referred to as pure task blocks, because subjects were performing trials in one condition at a time. Perhaps a better organization would be to conduct pure task blocks as well as mixed task blocks, to see if there were any differences in performance, as was done by Schumacher et al. (2001). When using this design, they found a difference in reaction times between the two types of trial blocks, and it was suggested that this was due to an increase in the requirement for subjects to prepare and maintain multiple task sets in the mixed task block compared to the pure task block. It was also said that separately estimating task-set and dual-task costs is useful determining the agerelated differences in dual-task performance. It has been shown by past research that 
older adults do have considerable difficulty when they need to be prepared to respond to multiple tasks as compared with a single task (Kray \& Lindenberger, 2000).

Another limitation is the use of two different spaces to conduct experiments, even if both areas were empty and provided sufficient space to accommodate errors. The young subjects were tested in the aerobics studio at the University of Ottawa, whereas older adults were tested at the community centre. Despite the differences in performances that might arise from utilizing two different spaces for conducting the experiments, subjects that could be tested in a familiar and convenient location would be more likely to participate, which was a deciding factor in the number of older subjects that were recruited. It was more appealing to attend to the testing session in their neighborhood, and schedule it between exercise classes, than having to travel to the University campus during the winter. 
Chapter IV

Conclusion 
The purpose of this study was to explore the impact of aging on the interaction between cognition and navigation. Much of the age-comparative work using the dualtask paradigm has the general expectation that older adults show greater dual-task costs than young adults because they have less attentional resources to simultaneously execute two or more tasks (Lindenberger et al., 2000). Disproportional age differences in dualtask costs are reported to vary as a function of task condition and differences are large when one or more of the tasks themselves impose high demands on cognitive processes. These might include focusing attention, scheduling and planning, updating and checking, as well as coding contextual representations (Salthouse et al., 1996).

Even though results of our pilot study shows that age differences in dual-task costs are statistically significant, and that dual-task costs do vary as a function of task condition, it would be of interest to consider conducting research on larger groups of older adults and investigate if any other factors would come into play when assessing their abilities to perform a blind navigation task, such as fitness levels and experience with complex orientation/navigation tasks.

Research done on navigation applies to psychology of perception, as well as physical rehabilitation. Some researchers are looking to develop rehabilitation outcome measures and interventions, which largely target older adults. Others aim to prevent primary and recurring falls (Lajoie \& Gallagher, 2004), which are more likely to occur in physically impaired or aging populations. To gain a better overall comprehension of the processes involved in navigation, multidisciplinary collaborations between experts specializing in different areas would be ideal. 


\section{Bibliography}

Allen, G., Kirasic, K, Rashotte, M. (2004). Aging and path integration skill: Kinesthetic and vestibular contributions to wayfinding. Perception and Psychophysics. 66 (1): 170179

Baltes, P. \& Lindenberger, U. (1997). Emergence of a powerful connection between sensory and cognitive functions across the adult life span : A new window to the study of cognitive aging? Psychology and Aging. $1: 12-21$

Bardy, B. \& Laurent, M. (1991). Vision, déplacement et demande en attention. Recherches en A.P.S. 3:179-190

Benhamou, S. \& Seguinot, V. (1995), How to find one's way in the labyrinth of path integration models. Journal of Theoretical Biology. 174:463-466

Berard, J., Fung, J., McFayden, B., Lamontagne, A. (2009). Aging affects the ability to use optic flow in the control of head during walking. Experimental Brain Research. 194(2): 183-190

Bertoz, A., Israel, I., Georges-Francois, P., Grasso, R., Tsuzuku, T. et al., (1995). Spatial memory of body linear displacement: what is being stored. Science. 269(5220): 95-98 
Bherer, L., Kramer, A.F., Peterson, M., Colcombe, S., Erickson, K. (2005). Training effects on dual-task performance: Are there age-related differences in plasticity of attentional control? Psychology and Aging. 20(4):695-709

Böök, A. \& Gärling, T. (1980). Processing of information about location during locomotion: effects of amount of visual information about the locomotor patterns. Perceptual Motor Skills. 51(1): 231-238

Bridgeman, B. \& Hoover, M. (2008). Processing spatial layout by perception and sensorimotor interaction. The Quarterly Journal of Experimental Psychology. 61(6): 851859

Brown, L.A., Shumway-Cook, A., Woollacott, M.H. (1999). Attentional demands and postural recovery: the effects of aging. Journal of Gerontology Series A: Biological Science and Medical Sciences. 54(4) M165-171

Canadian Institute for Health Information (CIHI) (2003). National trauma registry 2003 report: Injury hospitalizations (includes 2001-2002 data). Consulted November $12^{\text {th }}$, 2007.

Craig, J. \& Rollman, G. (1999). Somesthesis. Annual Review of Psychology. 50:301-331

Craik, F. \& Bialystok, E. (2006). Cognition through the lifespan : mechanisms of change. Trends in Cognitive Science. 10(3) :131-138 
Das, P. \& McCollum, G. (1988). Invariant structure in locomotion. Neuroscience. 25:1023-1034.

Day, B.L. \& Cole, J. (2002). Vestibular-evoked postural responses in the absence of somatosensory information. Brain. 125:2081-2088

Denis, M. \& Loomis, J. (2007). Perspectives on human spatial cognition: memory, navigation and environmental learning. Psychological Research. 71:235-239

Dietz, V. (2002). Proprioception and locomotor disorders. Neuroscience. 3:781-790

Elliott, D. (1986). Continuous visual information may be important after all: A failure to replicate Thomson (1983). Journal of Experimental Psychology: Human Perception and Performance.12:388-391

Elliott, D. (1987). The influence of walking speed and prior practice on locomotor distance estimation. Journal of Motor Behavior. 19: 476-485

Encyclopedia Britannica (2009). Inner ear. Encyclopedia Britannica Student and Home Edition (Ultimate Reference Suite).

Foley, J. (1985). Binocular distance perception: Egocentric distance tasks. Journal of Experimental Psychology: Human Perception and Performance. 11(2): 133-149 
Folstein, M.F., Folstein, S.E., McHugh, P.R. (1975). Mini-mental state : A practical method for grading the cognitive state of patients for the clinician. Journal of Psychiatric Research. $12: 189-198$

Fraizer, E.V. \& Mitra, S. (2008). Methodological and interpretive issues in posturecognition dual-tasking in upright stance. Gait \& Posture. 27:271-279

Fukusima, S.S., Loomis, J.M., Da Silva, J.S. (1997). Visual Perception of Egocentric Distance as Assessed by Triangulation. Journal of Experimental Psychology. 23(1):86100

Gallistel, C.R. (1990). The Organization of Learning. Cambridge, MA: Bradform Books/MIT Press.

Gazzaniga, Ivry and Mangun (1998). Cognitive Neuroscience. New York: Norton.

Gilinksy, A. (1951). Perceived size and distance in visual space. Psychological Review. 58(6): $460-482$

Glasauer, S., Amorim, M.A., Vitte, E., Berthoz, A. (1994). Goal directed linear locomotion in normal and labyrinthine-defective subjects. Experimental Brain Research. 98-323-335 
Glass, J.M., Schumacher, E.H., Lauber, E.J., Zurbriggen, E.L., Gmeindl, L. et al. (2000). Aging and the Psychological Refractory Period: Task-Coordination Strategies in Young and Old Adults. Psychology and Aging. 5(4):571-595

Guérin-Lajoie, M., Richards, C. L., McFayden, B. (2006). The circumvention of obstacles during walking in different environmental contexts: A comparison between older and younger adults. Gait \& Posture 24:364-369

Guérin-Lajoie, M., Ronskey, J., Loitz-Ramage, B., Robu, I., Richards, C.L., McFadyen, B.J. (2007). Navigational strategies during fast walking : A comparison between trained athletes and non-athletes. Gait \& Posture. 26: 539-545

Harper, M.E., Bevilacqua, L., Hagopian, K., Weindruch, R., Ramsey, J.J. (2004). Ageing, oxidative stress, and mitochondrial uncoupling. Acta Psychologica Scandinavia. $182: 321-331$

Haywood, K.M. \& Getchell, N. (2001). Life Span Motor Development. Windsor, Ontario: Human Kinetics.

Hegarty, M., Montello, D.R., Richardson, A.E., Ishikawa, T., Lovelace, K. (2006). Spatial abilities at different scales: Individual differences in aptitude-test performance and spatial layout learning. Intelligence. 34:151-176 
Israël, I., Grasso, R., Georges-François, P., Tsuzuku, T., Berthoz, A. (1997). Spatial Memory and Path Integration Studied by Self-Driven Passive Linear Displacement. I. Basic Properties. Journal of Neurophysiology. 77:3180-3192

Kanis, J.A. and the WHO Study Group (1994). Assessment of fracture risk and its application to screening postmenopausal Osteoporosis: Synopsis of a WHO report. Osteoporosis International. 4:368-381

Keele, S.W. (1968). Movement control in skilled motor performance. Psychological Bulletin. 70:387-403

Kerr, B., Condon, S., McDonald, L. (1985). Cognitive spatial processing and the regulation of posture. Journal of Experimental Psychology: Human Perception and Performance.11(5): 617-622

Kray, J. \& Lindenberger, U. (2000). Adult age differences in task switching. Psychology and Aging. 15(1):126-147

Lajoie, Y. \& Gallagher, S. (2004). Predicting falls within the elderly community: comparison of postural sway, reaction time, the Berg balance scale and the ActivitiesSpecific Balance Confidence (ABC) scale for comparing fallers and non-fallers. Archives of Gerontology and Geriatrics. 38: 11-26 
Lajoie ,Y., Teasdale, N., Bard, C., Fleury, M. (1993). Attentional demands for static and dynamic equilibrium. Experimental Brain Research. 97:139-144

Lajoie, Y., Teasdale, N., Bard, C., Fleury, M. (1996). Upright standing and gait: Are there changes in attentional requirements related to normal aging? Experimental Aging Research. 22: 185-198

Laurent, M., Paul, P., Cavallo, V. (1988). How is Gait Visually Regulated When the Head is Travelling Faster Than the Legs? Journal of Motor Behaviour. 20(3):301-316

Laurent, M. \& Thomson, J.A. (1988). The Role of Visual Information in Control of a Constrained Locomotor Task. Journal of Motor Behaviour. 20(1):17-37

Lindenberger, U., Marsiske, M., Baltes, P. (2000). Memorizing while walking : increase in dual-task costs from young adulthood to old age. Psychology and Aging. 13(3) : 417436

Lindberg, E. \& Gärling, T. (1982). Acquisition of locational information about reference points during locomotion: the role of central information processing. Scandinavian Journal of Psychology. 23(3): 207-218

Llewellyn, M., Yang, J.F., Prochazka, A. (1990). Human H-reflexes are smaller in difficult beam walking than in normal treadmill walking. Experimental Brain Research. $83: 22-28$ 
Loomis, J.M., Da Silva, J.A., Fujita, N., Fukusima, S.S. (1992). Visual Space Perception and Visually Directed Action. Journal of Experimental Psychology: Human Perception and Performance. 18(4):906-921

Loomis, J.M., Da Silva, J.A., Marques, S.L. (1987). Visual matching of spatial intervals and visually directed walking: A comparison. In: Rieser, J.J., Ashmead, D.H., Taylor, C.R., Youngquist, G.A. (1990). Visual perception and the guidance of locomotion without vision to previously seen targets. Perception. 19:675-689

Loomis, J.M., Klatzky, R.L., Golledge, R.G., Cicinelli, J.G., Pellegrino, J.W., Fry, P.A. (1993). Nonvisual navigation by blind and sighted: assessment of path integration ability. Journal of Experimental Psychology General. 1:73-91

Marieb, E. (1999). Anatomie et physiologie humaines. 2e Édition. Saint-Laurent, Qc: Éditions du renouveau pédagogique Inc.

Marsden, J.F., Castellote, J., Day, B.L. (2002). Bipedal distribution of human vestibularevoked postural responses during asymmetrical standing. Journal of Physiology. 542(1): $323-331$

Mittelstaedt, M.-L. \& Mittelstaedt, H. (2001), Idiothetic navigation in humans: estimation of path length. Experimental Brain Research. 139:318-332 
Moar, I. \& Carleton, L.R. (1982). Memory for routes. The Quarterly Journal of Experimental Psychology A. 34(Pt3): 381-394

National Osteoporosis Foundation. Consulted March 2009 at http://www.nof.org.

Newell, K.M. (2003). Schema theory (1975): retrospectives and prospectives. Research Quarterly for Exercise and Sport. 74:383-388

Ortega, J.D., Fehlman, L.A., Farley, C.T. (2008). Effects of aging and arm swing on the metabolic cost of stability in human walking. Journal of Biomechanics. 41(16): 33033308

Paquet, N., Lajoie, Y., Rainville, C., Sabagh-Yazdi, F. (2008). Effect of navigation direction on the dual-task of counting backward during blind navigation. Neuroscience Letters, doi :10.1016/j.neulet.2007.07.002

Paquet, N., Rainville, C., Lajoie, Y., Tremblay, F. (2007). Reproducibility of distance and direction errors associated with forwards, backwards and sideways walking in the context of blind navigation. Perception. 36: 525-536

Pashler, H. (1994). Dual-task interference in simple tasks: data and theory. Psychological Bulletin. 116: 220-244

Patla, A.E. (1991). Understanding the roles of vision in the control of human locomotion: a prologue. In: Shumway-Cook, A. \& Woollacott, M. (2001). Motor 
Control: Theory and Practical Applications. Baltimore, Maryland: Lippincott Williams \& Wilkins.

Péruch, P., Borel, L., Gaunet, F., Thinus-Blanc, C., Magnan, J., Lacour, M. (1999). Spatial performance of unilateral vestibular defective patients in nonvisual versus visual navigation. Journal of Vestibular Research. 9:37-47

Phillips, S.K., Wiseman, R.W., Woledge, R.C., Kushmerick, M.J. (1993). Neither changes in phosphorus metabolite levels nor myosin isoforms can explain the weakness in aged mouse muscle. Journal of Physiology. 463:157-167

Pozzo, T., Berthoz, A., Lefort, L. (1990). Head stabilization during various locomotor tasks in humans: 1. Experimental Brain Research. 82:97-106

Raibert, M. (1986) Symmetry in running. Science. 231:1292-1294

Rieser, J.J., Ashmead, D.H., Talor, C.R., Youngquist, G.A. (1990). Visual perception and the guidance of locomotion without vision to previously seen targets. Perception. $19: 675-689$

Rosenhall, U. \& Rubin, W. (1975). Degenerative changes in the human vestibular sensory epithelia. Acta Otolaryngologica. 79:67-81 
Salthouse, T.A., Hambrick, D.Z., Lukas, K.E., Dell, T.C. (1996). Determinants of adult age differences on synthetic work performance. Journal of Experimental Psychology. 2(4): $305-329$

Schmidt, R.A. (1982). Motor Control and Learning: A behavioral emphasis. Champaign, Illinois: Human Kinetics Publishers.

Schmidt, R.A. (2003). Motor schema theory after 27 years: reflections and implications for a new theory. Research Quarterly for Exercise and Sport. 74:366-375

Schmidt, R.A. \& Wrisberg, C.A. (2004). Motor Learning and Performance: A problembased learning approach (pp: 204). Windsor, Ontario: Human Kinetics Publishers.

Schumacher, E.H., Seymour, T.L., Glass, J.M., Fencsik, D.E., Lauber, E.J., Kieras, D.E., Meyer, D.E. (2001). Virtually perfect time-sharing in dual-task performance: Uncorking the central cognitive bottleneck. Psychological Science. 12:101-108

Shumway-Cook, A., Woollacott, M., Kerns, K.A. \& Baldwin, M. (1997). The effects of two types of cognitive tasks on postural stability in older adults with and without a history of fails. Journal of Gerontology: Medical Sciences. 52: M232-M240.

Shumway-Cook, A. \& Woollacott, M. (2001). Motor Control: Theory and Practical Applications. Baltimore, Maryland: Lippincott Williams \& Wilkins. 
Shumway-Cook, A. \& Woollacott, M. (2000). Attentional demands and postural control: the effect of sensory context. Journal of Gerontology. 55A:M10-16

Sparrow, W.A., Bradshaw, E.J., Lamoureux, E., Tirosh, O. (2002). Ageing effects on the attention demands of walking. Human Movement Science. 21: 961-972

Steenuis, R.E. \& Goodale, M.A. (1985). The effects of time and distance on accuracy of target-directed locomotion: Does an accurate short-term memory for spatial location exist? Journal of Motor Behaviour. 20: 399-415

Sturnieks, D.L., St George, R., Lord, S.R. (2008). Balance disorders in the elderly. Clinical Neurophysiology. 38:467-478

Teasdale, N., Bard, C., LaRue, J., Fleury, M. (1993). On the cognitive penetrability of postural control. Experimental Ageing Research. 19:1-13

Thomson , J.A. (1983). Is continuous visual monitoring necessary in visually guided locomotion? Journal of Experimental Psychology: Human Perception and Performance. 9(3): 427-443

Thomson, J.A. (1986). Intermittent versus continuous visual control: A reply to Elliott. Journal of Experimental Psychology: Human Perception and Performance. 12(3): 392393 
Verghese, J., Kuslansky, G., Holtzer, R., Katz, M., Xue, X., Bruschke, H., Pahor, M. (2007), Walking while talking : effect of task prioritization in the elderly. Archives of Physical Medicine and Rehabilitation. 88 :50-53

Weerdesteyn, V., Nienhuis, B., Geurts, A.C., Duyens, J. (2007). Age-related deficits in early response characteristics of obstacle avoidance under time pressure. Journals of Gerontology Series A: Biological Science and Medical Sciences. 62(9): 1042-1047

Wickens, C.D. (2008). Multiple resources and mental workload. Human Factors. 50(3): 449-455

Winter, D. (1980). Overall principle of lower limb support during stance phase of gait. Journal of Biomechanics. 13: 923-927

Winter, D. et al. (1990). Biomechanical Walking Pattern Changes in the Fit and Healthy Elderly. Physical Therapy. 70(6): 340-346

Woollacott, M. \& Shumway-Cook, A. (2002). Attention and the control of posture and gait : a review of an emerging area of research. Gait \& Posture. $16: 1-14$

Yang, J.F. \& Stein, R.B. (1990). Phase-dependent reflex reversal in human leg muscles during walking. Journal of Neurophysiology. 63(5): 1109-1117 
Yu, F., Hedström, M., Cristea, M., Dalén, N., Larsson, L. (2007). Effects of ageing and gender on contractile properties in human skeletal muscle and single fibres. Acta Physiologica (Oxford, England). 190:229-241

Zehr, P.E. \& Stein, R. (1999). What functions do reflexes serves during human locomotion? Progress in Neurobiology. $58: 185-205$ 


\section{Appendices}


Appendix I

Ethics approval 


\section{Université d'Ottawa University of Ottawa}

COMITÉ D'ÉTHIQUE DE IAA RFCHERCHF:

EN SCILNCES DE LA SANTÉ ET SCIENCES

ATTESTATION D'APPROBA TION ÉTHIQLE

La présente attestation ecrifie que le Comité d'ethique de la recherche (CÉR) en Sciences de la Santé et Sciences de l'Université d'Ottawa a examiné la demande de prolungation d'approbation éthique présentée par Yves Lajoie de l'École de sciences de lactivite physique et Nicole Paquet de l'École de sciences de la réadaptation de l'Université d'Ottawa pour le projet intitulé Exigences cognitives lors d'une tâche de navigation aveugle vers une cible chez de jeunes adultes et des personnes âgées (Dossier H08-06-16). Celui-ci avait initialement été approuvé par le CËR en Sciences de la Santé et Sciences le 7 novembre 2006, le CER de l'Université d'Ottawa ayant déterminé que la demande respectait les principes éthiques établis par l'Énoncé de politique des trnis conseils et par les règles de procédure des Comités d'éthique de l'Université d'Ottawa. Le CÉR accorde une prolongation de un (1) an, laquelle est valide jusqu'au 7 novembre 2008.

Gernain Zongo

Responsable de l'ćthique en recherche

Date

Pour Dr Danicl Lagarec. Président du CÉR en

Scicnces de la Santé et Sciences 
Appendix II

Health Status Questionnaire 


\section{Health Status Questionnaire}

Participant's Code:

Weight (kg):

Date of Birth (dd/mm/yy)

Have you fallen in the past six months? YES
Height (cm):

$\operatorname{Sex}(M / F)$

If you answered YES, please describe the circumstances that led you to fall. If you have fallen more than once, please use the backside of this sheet to describe the circumstances.

Are you currently taking any medication prescribed by a doctor? YES

NO

If you answered YES to the question above, please list them here:

Do you have any of the following medical conditions?

\begin{tabular}{|l|l|l|}
\hline An illness of the nervous system such as Parkinson or & YES & NO \\
Huntington. & & \\
\hline Heart disease or a past heart attack or stroke. & & \\
\hline Diabetes & & \\
\hline Injury to your upper-body in the past 6 months. & & \\
\hline Injury to your lower-body in the past 6 months. & & \\
\hline Loss of sensation (peripheral neuropathy) & & \\
\hline Arthritis in your lower body. & & \\
\hline Chronic back pain. & & \\
\hline Uncorrectable problems with your vision. & & \\
\hline
\end{tabular}




\section{Appendix III}

\section{Mini Mental State Examination}


Patient's code: Date:

Instructions: Score one point for each correct response within each question or activity.

\begin{tabular}{|c|c|c|}
\hline $\begin{array}{l}\text { Maximum } \\
\text { Score }\end{array}$ & $\begin{array}{l}\text { Patient's } \\
\text { Score }\end{array}$ & Questions \\
\hline 5 & & "What is the year? Season? Date? Day? Month?" \\
\hline 5 & & "Where are we now? State? County? Town/city? Hospital? Floor?" \\
\hline 3 & & $\begin{array}{l}\text { The examiner names three unrelated objects clearly and slowly, then } \\
\text { the instructor asks the patient to name all three of them. The patient's } \\
\text { response is used for scoring. The examiner repeats them until patient } \\
\text { learns all of them, if possible. }\end{array}$ \\
\hline 5 & & $\begin{array}{l}\text { "I would like you to count backward from } 100 \text { by sevens." }(93,86,79 \text {, } \\
72,65, \ldots) \\
\text { Alternative: "Spell WORLD backwards." (D-L-R-O-W) }\end{array}$ \\
\hline 3 & & $\begin{array}{l}\text { "Earlier I told you the names of three things. Can you tell me what those } \\
\text { were?" }\end{array}$ \\
\hline 2 & & $\begin{array}{l}\text { Show the patient two simple objects, such as a wristwatch and a pencil, } \\
\text { and ask the patient to name them. }\end{array}$ \\
\hline 1 & & "Repeat the phrase: 'No ifs, ands, or buts."' \\
\hline 3 & & $\begin{array}{l}\text { "Take the paper in your right hand, fold it in half, and put it on the floor." } \\
\text { (The examiner gives the patient a piece of blank paper.) }\end{array}$ \\
\hline 1 & & $\begin{array}{l}\text { "Please read this and do what it says." (Written instruction is "Close your } \\
\text { eyes.") }\end{array}$ \\
\hline
\end{tabular}




\begin{tabular}{|l|l|l|}
\hline 1 & & $\begin{array}{l}\text { "Make up and write a sentence about anything." (This sentence must } \\
\text { contain a noun and a verb.) }\end{array}$ \\
\hline 1 & "Please copy this picture." (The examiner gives the patient a blank \\
piece of paper and asks him/her to draw the symbol below. All 10 \\
angles must be present and two must intersect.)
\end{tabular}

Interpretation of the MMSE:

\begin{tabular}{|l|l|l|}
\hline Method & Score & Interpretation \\
\hline \hline Single Cutoff & $<24$ & Abnormal \\
\hline Range & $<21>25$ & Increased odds of dementia Decreased odds of dementia \\
\hline Education & $21<23<24$ & $\begin{array}{l}\text { Abnormal for 8th grade education Abnormal for high school education } \\
\text { Abnormal for college education }\end{array}$ \\
\hline Severity & $24-3018-23$ & No cognitive impairment Mild cognitive impairment Severe cognitive \\
& $0-17$ & impairment \\
\hline
\end{tabular}




\section{Interpretation of MMSE Scores:}

\begin{tabular}{|c|c|c|c|}
\hline Score & $\begin{array}{c}\text { Degree of } \\
\text { Impairment }\end{array}$ & Formal Psychometric Assessment & Day-to-Day Functioning \\
\hline $25-30$ & $\begin{array}{l}\text { Questionably } \\
\text { significant }\end{array}$ & $\begin{array}{l}\text { If clinical signs of cognitive impairment are } \\
\text { present, formal assessment of cognition may } \\
\text { be valuable. }\end{array}$ & $\begin{array}{l}\text { May have clinically significant but mild } \\
\text { deficits. Likely to affect only most } \\
\text { demanding activities of daily living. }\end{array}$ \\
\hline $20-25$ & Mild & $\begin{array}{l}\text { Formal assessment may be helpful to better } \\
\text { determine pattern and extent of deficits. }\end{array}$ & $\begin{array}{l}\text { Significant effect. May require some } \\
\text { supervision, support and assistance. }\end{array}$ \\
\hline $10-20$ & Moderate & $\begin{array}{l}\text { Formal assessment may be helpful if there } \\
\text { are specific clinical indications. }\end{array}$ & $\begin{array}{l}\text { Clear impairment. May require 24-hour } \\
\text { supervision. }\end{array}$ \\
\hline $0-10$ & Severe & Patient not likely to be testable. & $\begin{array}{l}\text { Marked impairment. Likely to require } 24 \text { - } \\
\text { hour supervision and assistance with ADL. }\end{array}$ \\
\hline
\end{tabular}

\section{Source:}

- Folstein MF, Folstein SE, McHugh PR: "Mini-mental state: A practical method for grading the cognitive state of patients for the clinician." J Psychiatr Res 1975; 12:189-198. 


\section{Appendix IV \\ Consent form}




\section{Consent form for study "Aging, Cognitive Functions and Spatial Navigation"}

\section{u Ottawa}

Université d'Ottawa

Faculté des sciences

de la santé

École des sciences de

l'activite physique

University of Ottawa Faculty of Health Sciences

School of Human Kinetics
Dr. Yves Lajoie, Universite d'Ottawa, Dr. Nicole Paquet, University of Ottawa

1 , , give consent to Dr. Yves Lajoie and Dr.

Nicole Paquet for my participation in a study on spatial navigation without vision.

I understand that:

The aim of the study is to determine the effects of aging and cognitive tasks on navigation errors during walking without vision. I will execute three tasks:

(1) Answering verbally "top" to auditory stimuli while sitting, (2) Walk towards previously seen targets at 8 meters without vision (3) Walk towards previously seen targets at 8 meters without vision while answering verbally "top" to auditory stimuli. After each trial of blind navigation, I will keep my eyes closed while the experimenter will bring me back to the starting point using different routes. There will be one testing session lasting 120 nrmuies

There is one risk to undertaking this study. The absence of vision during walking may provoke loss of balance, especially when I will be occupied to respond to the sound. In order to limit this risk, a research assistant will follow me closely to prevent me from falling.

The benefit of iny participation is a furthering of the knowledge regarding what makes people have errors in navigating their environment.

It is not anticipated that the testing session will cause any emotional discomfort. However, if it does, I will be provided with a list of qualified counsellors to whom I may be referred if needed.

I agree to participate in this study with the understanding that information will he collected and used for research purposes only and will be treated as confidential. I have been informed about the purpose of this study and realize that $I$ am under no obligation to participate and may withdraw at any time. Refusal to participate or withdrawing from the study will in no way affect my present and/or future status as a staff member of The Rehabilitation Centre or as a student at the University of Ottawa.

I will be identified in this study by my initials and assigned a subject number only. My confidentiality will be maintained at all times; and only the investigator will keep a record of my name. The data will be stored in a 
locked file cabinet for five years.

If I have any questions, or would like a copy of the study results, I can contact Dr. Yves Lajoie at (613) 5625800 , or Dr. Nicole Paquet at (613) 5625800 I can also contact the Protocol Officer for Ethics in Research, University of Ottawa, Tabaret Hall, 550 Cumberland Street.

I acknowledge that I have had the study and the contents of this consent form explained to me, that I understand this information and that I have received a copy of the consent form for my records. I understand that by accepting to participate, I am in no way waiving my right to withdraw from the study at any time.

Signed,

Participant's name: (Please print)

Participant's signature:

Date

Witness' signature:

Date 